\title{
Sentiment, Loss Firms, and Investor Expectations of Future Earnings
}

Abstract: This study investigates the mispricing of market-wide investor sentiment by exploring the relation between sentiment and investor expectations of future earnings. Prior research argues that sentiment-driven mispricing should be most pronounced for hard-to-value firms, such as those reporting losses (Baker and Wurgler 2006). Using investor expectations of future earnings, we provide empirical results consistent with this behavioral finance theory. In particular, we predict and find that investors perceive losses to be more (less) persistent during periods of low (high) sentiment; that investors perceive profit persistence to be lower (higher) during periods of low (high) sentiment; and that the effects appear stronger for loss firms relative to profit firms. In addition, we document predictable cross-sectional variation within losses, with the mispricing mitigated for losses associated with activities expected to generate future benefits: R\&D, growth, large negative special items, and severe financial distress. Overall, our results document a new and important channel-investor expectations of future earnings - to explain sentiment-driven mispricing, particularly for loss firms.

Key Words: investor sentiment, mispricing, earnings persistence, losses

JEL Classification: $D 21 ; G 02 ; G 11 ; M 41$

Data Availability: Data are publicly available from sources identified in the article. 


\section{Introduction}

Extant literature documents that systematic risk is not a complete explanation for observed changes in stock prices (Burger and Curtis 2012; Nichols et al. 2017). Rather, prior literature suggests that investor sentiment plays an important role in investors' information processing, and thus induces mispricing (Brown and Cliff 2005; Baker and Wurgler 2006, 2007; Hengelbrock et al. 2013; Coulton et al. 2016). These papers further argue that the compounding effects of being hard-to-value and more difficult to arbitrage should make the sentiment effect on stock valuation stronger for certain types of firms: those that are small, young, volatile, non-profitable, nondividends-paying, extreme growth, or distressed. While prior literature confirms these effects in several settings (Hribar and McInnis 2012; Mian and Sankaraguruswamy 2012; Seyber and Yang 2012; Kaplanski and Levy 2017), surprisingly limited evidence exists for loss firms. For instance, Mian and Sankaraguruswamy (2012) excludes loss firms from their primary tests, as the paper focuses on earnings response coefficients, which are uninformative for firms with negative earnings. Hribar and Mcinnis (2012) and Seybert and Yang (2012) conduct cross-sectional analyses on the relation between sentiment and returns on profit verses loss firms, but fail to find significant differences between the two groups. Kaplanski and Levy (2017) examines the sentiment effect on analyst forecasts; contrary to expectations under Baker and Wurgler, the paper finds that the forecasts of profitable firms are more affected by sentiment relative to those of loss firms.

In this paper, we assess the impact of sentiment on investor expectations of future earnings particularly for loss firms. The valuation process is generally viewed as more difficult for loss firms relative to profit firms. For example, while the market value of profit firms can be derived through multiples applied to current earnings, such techniques are infeasible for the negative 
earnings of loss firms. Prior research documents that the valuation of loss firms is largely driven by investors' perception of $R \& D$, restructuring charges, and the likelihood of exercising of liquidation, each of which involve substantial subjectivity (Joos and Plesko 2005; Darrough and Ye 2007; Franzen and Radhakrishnan 2009). Prior research further suggests that earnings forecasts are far less accurate for loss firms relative to profit firms: for example, Hwang et al. (1996) shows that the average analyst forecast error for loss firms is about ten times that for profit firms. This suggests greater difficulty for investors to predict the future earnings of loss-making firms, which comprise a significant and growing part of the overall market. ${ }^{1}$ Collectively, this suggests it is important to examine both how sentiment maps into loss firms, as well as the relative impact of sentiment on the pricing of profit versus loss firms.

Accordingly, we build on the literature investigating the channels that lead to investor mispricing (e.g., Sloan 1996; Baker and Wurgler 2007) and examine the impact of sentiment on investors' valuation of earnings for both profit and (more importantly) loss firms. Our primary outcome measure is the construct by Mishkin (1983), which examines investors' expected earnings persistence (i.e., future earnings given current period's earnings, denoted $a_{1}^{*}$ ) and firms' actual earnings persistence (denoted $a_{1}$ ). We combine these to investigate the link between sentiment and the errors in investor expectations of future earnings $\left(a_{1}^{*}-a_{1}\right)$. Thus, we link a wellestablished tool with assessing the effects of sentiment, which enables deeper insights into the mechanisms by which sentiment may affect equity pricing.

Psychology literature suggests that individuals tend to overvalue (undervalue) information that confirms (disconfirms) their beliefs (e.g., Edwards 1968; Lord et al. 1979; Nisbett and Ross 1980; Fiske and Taylor 1991). Consistent with the prior literature on sentiment, we apply this

1 For example, the percentage of loss firms increases from 2.2\% in 1973 to $32.2 \%$ in 2015. 
rationale to the current setting to derive our predictions of how sentiment should affect investor expectations of earnings persistence. We predict that during periods of low sentiment, investors will exhibit more pessimism about firms' future prospects; this will cause a tendency to overweigh negative (and underweigh positive) signals of firm performance. This leads to our expectation that during periods of low sentiment, investors expect losses to be more persistent and profits to be less persistent relative to their actual persistence. In contrast, during periods of high sentiment where investors exhibit greater optimism, we predict that investors are more likely to perceive current losses as less persistent, and current profits as more persistent.

To examine these expectations, we use quarterly data to capture all earnings announcements throughout the year. We use two specifications for investor expectations: a random walk model; and a seasonal random walk model. The random walk model assumes the expected earnings for the next quarter is a function of earnings in the current quarter; the seasonal random walk model assumes the expected earnings for the next quarter is a function of earnings in the same quarter of the prior year. Note that we use reported earnings, as opposed to analyst forecasts to assess investor expectations, for two primary reasons. First, this ensures a more general representation of loss firms. In particular, prior research confirms that analyst coverage is limited for young, small, and distressed firms (Hou et al. 2012; Li and Mohanram 2014; Keskek et al. 2019). As such, using analysts' forecasts to proxy for market's expectations may cause sampling biases, and impede our ability to assess a broad sample of loss-making firms. Second, prior research documents that analysts have incentives to bias their forecasts, which may limit using such forecasts to capture market expectations (e.g., Francis and Philbrick 1993; Dugar and Nathan 1995; McNichols and O’Brien 1997; Lin and McNichols 1998; Richardson et al. 2004; Easton and Sommers 2007). 
Consistent with our predictions, we find that sentiment plays an important role in forming investor expectations of future earnings. Specifically, we document that investors overweigh (underweigh) loss persistence in low (high) sentiment periods. We also find contrasting (albeit weaker) evidence for profit firms: investors overweigh (underweigh) profit persistence in high (low) sentiment periods. Statistical comparisons of these effects confirm that the effects of sentiment are stronger for loss firms relative to those for profit firms. These latter findings are consistent with prior research suggesting that sentiment-driven mispricing should be more prevalent for hard-to-value firms, such as loss firms (Baker and Wurgler 2006).

To further assess the above average relation, we next investigate whether the mispricing of loss persistence varies with characteristics of the reported losses. Prior research documents heterogeneity in how investors view current period losses (Francis et al. 1996; Burgstahler et al. 2002; Joos and Plesko 2005; Darrough and Ye 2007; Franzen and Radhakrishnan 2009; Li 2011). For example, investors differentially price losses for firms having expenditures with potential longterm pay-offs (e.g., R\&D), or for firms likely to return to profits if they decide to liquidate lossgenerating assets and curtail loss-making operations (Hayn 1995; Lawrence et al. 2017). Accordingly, we expect that the effect of sentiment in reducing the perceived persistence of earnings for loss firms will be mitigated for certain types of losses that may convey positive information regarding firms' future performance: (i) those arising from high $\mathrm{R} \& \mathrm{D}$ expenditures; (ii) those for firms exhibiting high growth potential; (iii) those arising from large negative special items - including write-downs, restructuring charges, and goodwill impairments; and (iv) and those for firms exhibiting severe financial distress. Prior research argues that across all four scenarios, the depressed current earnings can be viewed as transitory, and thus be more likely to 
reverse in the future. ${ }^{2}$ Consistent with these expectations, our cross-sectional analyses confirm that the mispricing of loss persistence driven by sentiment is attenuated for loss firms with high R\&D, high growth potential, large negative special items, and severe financial distress.

This paper makes four contributions. First, it complements Mian and Sankaraguruswamy (2012) by extending their analysis (which focuses on profit firms) to demonstrate that the sentiment effect on investors' valuation of accounting information also occurs for loss firms. These insights are important, given the substantial proportion of loss firms in the market, as well as the inconclusive evidence of recent studies regarding the strength of the sentiment effect across loss versus profit firms (Hribar and McInnis 2012; Mian and Sankaraguruswamy 2012; Seybert and Yang 2012; Walther and Willis 2013; Kaplanski and Levy 2017). Second, recent papers provide evidence that the association between stock price and accounting fundamentals has weakened at the aggregate level, and varies substantially across different types of firms (Curtis 2012; Burger and Curtis 2017; and Nichols et al. 2017). Our study provides a plausible explanation that such mispricing may, in part, reflect sentiment-driven mispricing on a large and growing subset of firms: those incurring losses. Third, this study provides evidence of heterogeneity in these effects across loss firms; in particular, the sentiment-driven mispricing for loss firms is mitigated when losses are associated with activities expected to have a positive impact on firms' future performance: $\mathrm{R} \& \mathrm{D}$, growth, large negative special items, and severe financial distress. Thus, we complement prior research examining how investors condition their perceptions on the nature of the reported loss (e.g., Joos and Plesko 2005; Darrough and Ye 2007). Finally, this study contributes to the literature on sentiment-driven mispricing by suggesting a new and important channel through which sentiment maps into firm valuation. Mian and Sankaraguruswamy (2012)

2 Providing tension in this expectation: loss firms with these attributes could face more uncertainty in their future operations, and thus be more difficult to value or arbitrage. 
suggests that investor sentiment affects market pricing by influencing the stock price sensitivity per unit of earnings surprise (i.e., earnings response coefficient, or ERC). Our results reveal that sentiment directly impacts investors' expected future earnings: thus, sentiment not only affects the market reaction per unit price of ex post earnings surprise, but also the magnitude of earnings surprise through investors' formation of ex ante earnings expectations.

Section 2 presents the literature and hypotheses; Section 3 presents the research design; Section 4 presents the sample selection and descriptive analyses; Section 5 presents the empirical results; and Section 6 presents the additional analyses. Section 7 concludes.

\section{Literature review and hypotheses development}

\section{Prior Literature}

This paper builds on two literatures: that examining sentiment and the related role of accounting; and that relating to investor expectations of future earnings, in particular, for loss firms. Regarding the first, prior research in psychology argues that sentiment plays a significant role in how individuals perceive information and make decisions. Of note, the extant literature provides evidence supporting the "confirmation bias" theory: individuals overweigh information that supports their beliefs, and dismiss information that does not (Edwards 1968; Lord et al. 1979; Nisbett and Ross 1980; Fiske and Taylor 1991).

Accounting and finance literature introduces the concept of sentiment into capital market studies, revealing that investor sentiment is a key input for firm valuation. Baker and Wurgler (2007) finds a positive relation between sentiment and stock returns in the cross-section, documenting that sentiment-driven mispricing is more pronounced for hard-to-value and hard-toarbitrage stocks. Subsequent studies show that sentiment affects the pricing of accounting 
information. Ali and Gurun (2009) and Livnat and Petrovits (2009) focus on the accrual component of earnings, finding that investors tend to overvalue (undervalue) the accrual component during high (low) sentiment periods. Bagnoli et al. (2014) also finds that analysts are affected by sentiment and tend to issue more favorable stock recommendations when recent and future sentiment is more bullish. Mian and Sankaraguruswamy (2012) links the mispricing to investors' reaction to per unit of earnings surprise (measured by the earnings response coefficient, or ERC); the paper shows that investors place optimistic (pessimistic) valuations on earnings surprises during periods of high (low) sentiment. ${ }^{3}$ Finally, Hribar and McInnis (2012) and Walther and Willis (2013) extend Baker and Wurgler (2006, 2007), and argue that analysts' expectation errors drive the association between sentiment and stock returns in a cross-sectional setting. We note two key differences between our study and these two latter papers. First, we examine the market reaction at a more general level: that is, instead of an analysis of analysts' pricing behavior to measure investor expectation, we directly examine sentiment-driven biases for all investors. Of particular note, the use of analyst forecasts as a proxy for investor expectation leads to selection biases that move the sample towards larger firms with analyst following. This is relevant, as loss firms tend to be smaller and lack analyst following. Thus, our use of market implied earnings forecast errors enables us to focus the analyses on a broader subset of firms (loss firms) that is motivated by prior research to be a set wherein the effects of sentiment are likely exacerbated (i.e.,

3 Our study differs from Mian and Sankaraguruswamy ("MS", 2012) in that the latter paper investigates how sentiment affects the ERC, while we investigate how sentiment affects investor expectations of earnings. The ERC and unexpected earnings affect the earnings-return relation through different channels. We further discuss the differences between our analyses and MS in Section 3 (the research design). Finally, we note that MS fails to find significant effects for sentiment on the ERC of loss firms. However, we highlight that these latter results can reflect either that the null is true (i.e., that there is no effect of sentiment on the ERC of loss firms, as concluded by MS), or that issues with the model implementation result in the failure to reject (e.g., power, variable measurement, and specification; see Wooldridge 2013). Given prior research's conclusions that ERC models do not perform well for loss firms (e.g., Hayn 1995; Collins et al. 1997), the latter explanation appears at least feasible. 
hard-to-value firms, as argued in Baker and Wurgler 2006). Second, we highlight that a primary focus of our study is to assess the differential impact of sentiment on the profit and loss expectations, and further to examine whether loss heterogeneity leads to variations on the sentiment effect. In contrast, Walther and Willis (2013) uses a pooled sample, and does not differentiate these two (key) subgroups.

The impact of sentiment is prevalent to all types of stocks. Abreu and Brunnermeier (2003) presents a model in which asset mispricing persists despite the presence of rational arbitrageurs due to their inability to fully implement a timely trading strategy. However, prior research argues that sentiment has cross-sectional effects: that is, the effect should be most pronounced for those firms that are harder to value and/or harder to arbitrage. Baker and Wurgler (2006) provides early cross-sectional evidence consistent with this notion, with subsequent studies confirming that high volatility, non-dividend-paying, distressed, and extreme growth stocks are more subject to sentiment (Lemmon and Portniaguina 2006; Mian and Sankaraguruswamy 2012). Of note among these cross-sectional effects is the lack of focus and inconclusive results for the effect of sentiment on loss firms. For example, Mian and Sankaraguruswamy (2012) excludes observations with negative earnings from all primary analyses: the paper focuses on ERCs, which are uninformative for loss firms (Hayn 1995; Collins et al. 1997). In addition, Hribar and McInnis (2012) fails to find significant correlations between sentiment and portfolio returns for loss relative to profit firms. Furthermore, Seybert and Yang (2012) examines the sentiment effect on the returns centered on management guidance issuance dates, also failing to find differences between loss versus profit firms. Finally, Kaplanski and Levey (2017) examines the sentiment effect on analyst forecasts and finds that, contrary to Baker and Wurgler's argument, sentiment has a greater effect on the forecasts of profit relative to loss-making firms. 
As such, prior research is inconclusive on whether the sentiment effect exists for loss firms, and (if so) its effect relative to profit firms. Compounding these inconclusive results is the common implementation using analyst forecasts to assess investor expectations, which creates likely sample selection biases that exclude large subsets of loss-making firms. Accordingly, this represents an important gap in the sentiment literature: as Baker and Wurgler (2006, 2007) documents, loss firms are harder to value or harder to arbitrage, which suggests that loss firms represent an important subset of firms to examine in their own right, and also provide an important benchmark relative to profit firms. ${ }^{4}$

Regarding the literature examining investor expectations of future earnings, prior studies suggest that investors do not predict the persistence of the earnings components rationally. Sloan (1996) and Dechow and Ge (2006) report that investors fail to anticipate the lower persistence of either the accruals or special items components. More importantly, losses have been shown as less persistent than profits, making losses less informative about firm value than profits. For example, prior research provides consistent evidence suggesting that the informativeness of losses with respect to firms' future cash flows is limited due to a liquidation option (e.g., Hayn 1995; Berger et al. 1996; Subramanyam and Wild 1996; Burgstahler and Dichev 1997; Barth et al. 1998; and Lawrence et al. 2017).

4 Baker and Wurgler (2006) posits that loss firms are more sensitive to change of sentiment for two reasons. First, sentiment-sensitive stocks are more difficult to value and thus more subject to speculative demand; and second, these stocks are also more risky and costly to arbitrage. Several other studies adopt this theory, but do not distinguish these two channels as both lead to similar predictions on the magnitude of the sentiment effect (Baker and Wurgler 2006; Lemmon and Portniaguina 2006; Mian and Sankaraguruswamy 2012). Following previous studies, we do not distinguish the "hard to value" and "difficult to arbitrage" effects, and believe that both are captured within our study. Hayn (1995) and Collins et al. (1999) find that loss firms are more difficult to value than profit firms because losses tend to be transitory and less indicative of future performance. This strongly suggests that our comparison of loss versus profit particularly captures the differential sentiment effects on "hard to value" and "easy to value" firms. 
Lower loss persistence also adds uncertainty for analysts and investors to evaluate firms' future performance given current losses. Hwang et al. (1996) finds that the average analyst forecast error for loss firms is about ten times that for profit firms. Related, $\mathrm{Li}$ (2011) examines investors' understanding of loss persistence, finding that investors cannot fully distinguish persistent from transitory losses, and instead assume that all losses are transitory. Our study builds upon the findings of $\mathrm{Li}$ (2011) by examining the moderating role of sentiment on investors' expectation of earnings (both profit and loss) persistence.

\section{Hypothesis development}

This study investigates the relation between market-wide sentiment and errors in investor expectations of future earnings given current earnings. We measure errors as investors' perceived earnings persistence relative to firms' actual earnings persistence. We focus on loss firms and profit firms separately, because prior research suggests that sentiment has a differential impact on hard-to-value stocks, such as loss firms (Baker and Wurgler 2006).

Individuals tend to overvalue (undervalue) information that confirms (contradicts) their prior beliefs (Edwards 1968; Lord et al. 1979; Nisbett and Ross 1980; Fiske and Taylor 1991). Accordingly, we predict that investors tend to overreact to financial information that is consistent with their prior sentiment, and conversely underreact to financial information that is inconsistent with their prior sentiment. This leads to our expectation that when investors observe firms reporting a loss during periods of low sentiment, they will overweigh the implication of current losses on future earnings. In contrast, when investors observe firms reporting a loss during periods of high sentiment, they are more likely to show optimistic expectations of future earnings: that is, to view current losses as more transitory and that such firms will more quickly return to profitability. We predict similar, although opposite in sign, associations for profit firms: during 
low sentiment periods, investors place lower persistence on current profit; and during high sentiment periods, investors place higher persistence on current profits. Taken together, our first hypotheses (stated in the alternative form) are:

$\mathrm{H}_{1 \mathrm{~A}}$ Investors perceive losses as more persistent in low sentiment periods and less persistent in high sentiment periods.

$\mathrm{H}_{1 \mathrm{~B}}$ Investors perceive profits as less persistent in low sentiment periods and more persistent in high sentiment periods.

Note that we benchmark investor expectations of earnings persistence with firms' actual earnings persistence. That is, we define errors in investor expectations as the difference between the perceived versus actual persistence coefficient. Thus, $\mathrm{H}_{1 \mathrm{~A}}$ predicts a negative relation between sentiment and errors in investor expectations of future earnings for loss firms. Similarly, $\mathrm{H}_{1 \mathrm{~B}}$ predicts a positive relation between sentiment and these errors for profit firms. ${ }^{5}$

Next, we examine if the mispricing of loss persistence differs by the nature of the reported loss. In particular, we consider whether heterogeneity in why firms report losses leads to variation in how sentiment affects investor expectations of future earnings for such firms. Extant research argues that the sentiment effect should be more pronounced on firms that are hard-to-value or more difficult to arbitrage (Baker and Wurgler 2006; Lemmon and Portniaguina 2006; Mian and Sankaraguruswamy 2012). We build on this literature and identify four categories of loss firms that satisfy such condition: (i) those with high research and development (R\&D); (ii) those with high growth potential; (iii) those reporting large negative special items; and (iv) those under high financial distress. On the one hand, investor sentiment can be accentuated for these four categories of loss firms since they face more uncertainty in their future operations, and thus are more difficult

5 Restated, we predict that lower sentiment is associated with higher perceived loss persistence relative to actual loss persistence; and (conversely) that higher sentiment is associated with lower perceived loss persistence relative to actual loss persistence. 
to value. As Baker and Wurgler (2006) argue, the sentiment effect should be more pronounced on firms that are harder to value and arbitrage. On the other hand, however, prior research suggests these four categories of loss firms are more likely to return to profitability due to their nature of the losses. This leads to an alternative expectation that the sentiment effect may be weaker for these loss firms, if investors believe these losses as more likely to be transitory and/or conveying positive signals about companies' future performance. We consider each category individually.

Regarding (i)—loss firms with high R\&D, US GAAP requires the expensing of (most) $R \& D$ expenditures. However, prior research finds that $R \& D$ expenditures have a positive impact on the valuation for loss firms. Joos and Plesko (2005) finds that investors understand the different valuation implications of the $R \& D$ versus non- $R \& D$ components of losses, and price the $R \& D$ component as an asset. Similarly, Darrough and Ye (2007) documents that investors positively value the $R \& D$ for loss firms, and that separating $R \& D$ from earnings substantially reduces the negative relation between market values and earnings for these firms. Finally, Franzen and Radhakrishnan (2009) examines the valuation implications of R\&D on profit versus loss firms, finding that $R \& D$ expenses are positively associated with stock prices for loss firms. This suggests that while R\&D has uncertainty regarding its future pay-off, some studies suggest that investors perceive $R \& D$ as having future pay-offs (on average) for loss firms.

Regarding (ii) — loss firms with high growth potential, such firms are likely viewed more positively than loss firms with low or no growth. For example, a firm in the early stage of its life cycle is more likely focusing on expanding market share than growing its current earnings (e.g., consider the historical performance of Amazon). Similarly, a firm with a first-mover advantage or innovative idea is likely to incur large initial investments and thus show low (or negative) earnings. If investors understand firms' growth strategy and choose to focus more on future 
earnings growth potential, then they are less likely to penalize the valuation of such firms despite the reporting of current period losses.

Regarding (iii)—-loss firms with large negative special items, we note that special items comprise non-recurring items, including impairments, write-downs, and restructurings (Riedl and Srinivasan 2010). Prior research suggests that some special items generate future benefits, such as positive future returns in the context of restructuring charges (Francis et al. 1996), and increased future earnings (Burgstahler et al. 2002; Cready et al. 2012) consistent with "big bath" reporting behavior. If investors understand the temporary nature of special items and its implication on future earnings, then they are less likely to overweigh loss persistence when losses contain a significant proportion of special items.

Finally, regarding (iv) — loss firms with high financial distress, we note that losses cannot persist indefinitely: profitability is a maintained hypothesis of a business entity. Accordingly, such firms should rationally take actions to avoid persistent losses such as liquidating loss-generating assets (Hayn 1995). Lawrence et al. (2017) investigates the role of curtailment in explaining the lower persistence of losses relative to profit, finding that curtailments are an important determinant of lower loss persistence. If investors perceive that a loss firm in severe financial distress can engage in curtailment and turn the poor performance around, then they are likely to provide a less negative or even positive valuation. ${ }^{6}$

In summary, based on prior research, we posit the sentiment effect on investor expectations of loss persistence is attenuated for loss firms with (1) high R\&D; (2) high growth potential; (3) large negative special items; and (4) high financial distress if the associated losses are viewed as

6 However, we note that investors may overweigh loss persistence during low sentiment periods if they view financial distress increasing firm uncertainty. However, severely distressed firms are likely to be delisted, and thus not in our sample. As such, this may lead the curtailment story instead of the persistent loss story to be more evident in our setting. 
more likely to be transitory and not signaling firms' future performance. Ostensibly, such firms are likely more difficult to value and/or arbitrage, suggesting the sentiment effect will be accentuated for such firms. Accordingly, we present the following non-directional hypothesis (in the null form):

$\mathrm{H}_{2}$ Mispricing of loss persistence driven by sentiment is not affected by whether the losses are associated with high $R \& D$, high growth potential, large negative special items, or high financial distress.

\section{Research design}

\section{Investor expectations of earnings persistence}

We use the Mishkin (1983) framework to measure actual and expected earning persistence. Sloan (1996) introduces this framework into the accounting literature; subsequent studies use it to examine the market efficiency of earnings (e.g., Xie 2001; Dechow and Ge 2006; Li 2011). We follow prior research, and measure the earnings persistence between quarter $t$ and quarter $t+1$ by estimating one "forecast equation" and one "pricing equation":

Forecasting equation: $R O A_{i, t+1}=a_{0}+a_{1} R O A_{i, t}+e_{i, t+1}$

Pricing equation: $\quad B H A R_{i, t+1}=b\left(R O A_{i, t+1}-a_{0}-a_{1}^{*} R O A_{t i,}\right)+\varepsilon_{i, t+1}$

where $R O A_{i, t}\left(R O A_{i, t+1}\right)$ equals earnings before extraordinary items for fiscal quarter $t(t+1)$ scaled by total assets at the beginning of quarter $t(t+1)$ for firm $i$. Consistent with Li (2011), we define $B H A R_{i, t+1}$ as the buy-hold value-weighted size-adjusted return over the period starting two trading days after the earnings announcement date of quarter $t$ and ending one trading day after the earnings announcement date of quarter $t+1$ for firm $i .^{7}$

7 We alternatively replace the quarterly abnormal returns in Equation (2) by a short-period return, which is the cumulative abnormal returns over the three-trading-day window around the earnings announcement date of quarter $t+1$. Consistent with Baker and Wurgler (2006), the results are insignificant. This is unsurprising as earnings news is released gradually throughout the quarter by analysts and management (i.e., preannouncements, conference 
Our key construct — errors in investor expectations of future earnings - is defined as:

$$
\begin{aligned}
\operatorname{ERROR}_{i, t+1} & =R_{O A_{i, t+1}} \text { expected } R O A_{i, t+1} \\
& =\left(a_{0}+a_{1} R O A_{i, t}\right)-\left(a_{0}+a_{1}^{*} R O A_{i, t}\right) \\
& =\left(a_{1}-a_{1}^{*}\right) R O A_{i, t}
\end{aligned}
$$

The error in investor expectations of earnings persistence equals the amount by which investors' expected earnings persistence coefficient $\left(a_{1}^{*}\right)$ deviates from the actual earnings persistence coefficient $\left(a_{1}\right)$ conditional on current earnings; restated, it is $\left(a_{1}-a_{1}^{*}\right)$. Our empirical analyses use $a_{1}^{*}-a_{1}$ to simplify the exposition: a positive (negative) $a_{1}^{*}-a_{1}$ indicates investors' overvaluation (undervaluation) of earnings persistence. We focus on $a_{1}^{*}-a_{1}$ versus $a_{1}^{*}$ because both $a_{1}^{*}$ and $a_{1}$ can be affected by sentiment contemporaneously. ${ }^{8}$ Under a null of market efficiency, $a_{1}^{*}-a_{1}=0$ : that is, investors' expected earnings persistence equals actual earnings persistence. Thus, $a_{1}^{*}-a_{1}>0$ is consistent with investors overestimating earnings persistence; and $a_{1}^{*}-a_{1}<0$ is consistent with investors underestimating earnings persistence.

We highlight that our variable of interest (investor perceived earnings persistence $a_{1}^{*}$ ) differs from the earnings response coefficient (ERC) as follows. The ERC is the beta coefficient on the unexpected earnings (Equation (2) above), and indicates how $\$ 1$ of unexpected earnings maps into stock returns. Unexpected earnings in the Mishkin model is calculated using a random walk model or an earnings persistent model; that is, earnings on $t+1$ is forecasted using earnings on $t$ (Equation (1) above). In other words, expected earnings on $t+1$ (Equation (2) above) is calculated using actual earnings and an investor perceived earnings persistence coefficient on $t$.

calls, management guidance, and analysts forecast revisions). As such, we assume that adjustments of investors' expectations will also occur gradually over a quarter, and thus is unlikely captured by a three-day trading window.

8 For example, if high sentiment increases the persistence of current profit to the next period earnings, then a high $a_{1}^{*}$ may not indicate investors' over-estimated earnings expectation but rather a rational expectation of the underlying growth. 
Our objective is to test how sentiment affects investor expectations of earnings persistence; that is, how sentiment affects $a_{1}^{*}$, which then affects the expected earnings (and consequently also unexpected earnings) in the pricing model in the Equation (2) above. In this simple model, sentiment directly affects the unexpected earnings component, not the beta/ERC coefficient; the latter is the focus of Mian and Sankaraguruswamy (2012). Critically, we focus on assessing the effect of sentiment on the magnitude of unexpected earnings (versus on Beta) as it allows us to (a) focus on a component that is less likely subject to the measurement/model concerns of the ERC for loss firms; and (b) directly measure a specific component that investors are using in their valuation as opposed to the ERC, which combines earnings persistence, risk, growth, and the discount rate in the valuation (Collins and Kothari 1989).

\section{Measurement of investor sentiment}

Our primary measure of investor sentiment is the composite sentiment index of Baker and Wurgler (2006), updated by prior research. It reflects five sentiment proxies: the closed-end fund discount; the number, and average first-day returns on IPOs; the equity shares in new issues; and the dividend premium. To separate this measure from common economic fundamentals, the index is orthogonalized to the following market-wide components: growth in industrial production; the growth in durable, nondurable, and services consumption; the growth in employment; and a flag for NBER recessions (Baker and Wurgler 2006). We also use an alternative sentiment measure, the University of Michigan Consumer Sentiment, in the sensitivity analyses.

To examine how sentiment affects investor expectations of quarter $t+1$ earnings given quarter $t$ earnings, we construct a quarterly sentiment measure $\left(S E N T_{t}\right)$ by averaging the monthly Baker-Wurgler index from the month immediately after the earnings announcement of quarter $t$ to 
the month before the earnings announcement of quarter $t+1$. We start from the month after the earnings announcement of quarter $t$ to capture investor sentiment after the current period's earnings are known; we end in the month before the quarter $t+1$ earnings announcement to prevent the sentiment measure from contamination by the release of quarter $t+1$ earnings.

As discussed below, the empirical tests examine the relation between sentiment $\left(S E N T_{t}\right)$ and errors in investor expectations of earnings persistence $\left(\alpha_{1}^{*}-\alpha_{1}\right)$ by performing a rank univariate analysis, a grouping regression analysis, and a monthly regression analysis.

\section{Univariate analysis}

As sentiment is expected to have a differential impact on profit and loss firms, all analyses separately examine loss and profit firms; loss (profit) firms are those with income before extraordinary items less (greater) than zero. We then partition the loss and profit samples into quintiles based on the level of investor sentiment: quintile 1 (quintile 5) includes observations in the lowest (highest) sentiment periods. For loss firms, we predict that investors consider losses to be more (less) persistent when they are pessimistic (optimistic); this is consistent with a significantly positive error (i.e., $a_{1}^{*}-a_{1}>0$ ) in the low sentiment periods, and a negative error in the high sentiment periods. This further leads to an expected negative relation between errors in investor expectations of earnings persistence and sentiment across the quintiles. We predict the reverse for profit firms: a significantly negative (positive) $a_{1}^{*}-a_{1}$ during periods of low (high) sentiment, and a monotonic increase in $a_{1}^{*}-a_{1}$ as sentiment increases.

\section{Multivariate analysis}

Prior literature documents that the mispricing of investor sentiment is more pronounced for difficult-to-value firms (D’Avolio 2002; Geczy et al. 2002; Jones and Lamont 2002; Baker and 
Wurgler 2006). Accordingly, we examine the relation between sentiment and $a_{1}^{*}-a_{1}$ in a multivariate setting controlling for six firm characteristics that capture difficulty to value: firm size $(S I Z E)$, measured as the logged market capitalization in quarter $t$; sales growth $(S G)$, measured as firm sales in quarter $t$ minus sales in quarter $t$ - 1 , divided by sales in quarter $t-1$; age (AGE), measured as the number of years since the firm first appeared on CRSP (assessed to the nearest month); dividend payment (DIV), measured as total dividend paid divided by the book value of equity in quarter $t$; stock volatility (VOLA), measured as the standard deviation of daily returns over the three months ending in quarter $t$; and the percentage of tangible assets (PPE), measured as property, plant, and equipment scaled by total assets in quarter $t$ (see the Appendix).

We conduct two alternative regressions: a grouping analysis and a monthly analysis. For the grouping analysis, we rank all loss (profit) observations into 100 groups (and thus 100 observations). ${ }^{9}$ For each group, we calculate the mean values of sentiment (denoted $S E N T_{-} G_{t}$ ), the six control variables, and $a_{1}^{*}-a_{1}$. We then estimate the following regression:

$$
a_{1}^{*}-a_{1}=c_{0}+c_{1} S E N T_{-} G_{t}+\sum C O N T R O L_{-} G_{t}+\delta_{t}
$$

As previously, $a_{1}^{*}-a_{1}$ is investor perceived earnings persistence relative to the actual earnings persistence (i.e., the errors in investor expectations of future earnings). $S E N T_{-} G_{t}$ is the average Baker and Wurgler (2006) sentiment index from the month after the earnings announcement of quarter $t$ to the month before the earnings announcement of quarter $t+1$ for each of the 100 groups. Following $\mathrm{H}_{1 \mathrm{~A}}$, we expect a negative coefficient on $S E N T_{-} G_{t}$ for loss firms, suggesting that investors overvalue (undervalue) loss persistence in low (high) sentiment periods. Following $\mathrm{H}_{1 \mathrm{~B}}$, we expect a positive coefficient on $S E N T_{-} G_{t}$ for profit firms, suggesting that investors overvalue (undervalue) profit persistence in high (low) sentiment periods.

9 We select 100 groups to ensure sufficient observations within each group to perform the Mishkin test. Untabulated results are unchanged to alternatively using 50 and 150 groups. 
For the monthly analysis, we group observations by each month/year based on the firm's fiscal quarter end. This aligns sentiment with errors in investor expectations of future earnings by time. For example, we include all firms with the fiscal quarter ended in March 2000 as one group, and for this group calculate the set of $a_{1}^{*}-a_{1}$ by performing Mishkin tests, the means of sentiment (denoted $\left.S E N T_{-} M_{t}\right)$ and the mean values of six control variables $\left(C O N T R O L_{-} M_{t}\right)$. Our sample spans 1973-2015, with a maximum of 516 (43 years x 12 months/year) monthly observations; our analyses use fewer observations due to insufficient sample sizes within certain months to allow the Mishkin test to converge. We perform the following regressions:

$$
a_{1}^{*}-a_{1}=c_{0}+c_{1} S E N T_{-} M_{t}+\sum C O N T R O L_{-} M_{t}+\delta_{t}
$$

All control variables are defined as in Equation (4). As above, we predict a negative coefficient on $S E N T_{-} M_{t}$ for loss firms $\left(\mathrm{H}_{1 \mathrm{~A}}\right)$, and a positive coefficient on $S E N T_{-} M_{t}$ for profit firms $\left(\mathrm{H}_{1 \mathrm{~B}}\right)$.

\section{Cross-sectional analyses for loss firms}

Finally, we test the mispricing of loss persistence by partitioning losses into four categories; these partitions are motivated by expectations that investors view losses heterogeneously. First, firms with high $R \& D$, measured as quarterly observations with $R \& D$ scaled by total assets in the top quartile; low $R \& D$ includes all other observations. For this analysis, we replace missing R\&D with zero. Second, firms with high growth potential, measured as quarterly observations with book-to-market ratios in the bottom quartile; low growth includes all other observations. Third, firms reporting large negative special items, measured as quarterly observations with special items divided by total assets in the bottom quartile; small (or no) special items include all other observations. Fourth, firms under severe financial distress, measured as observations with a financial distress score (calculated annually for the prior fiscal year) in the bottom quartile; low 
financial distress includes all other observations. The financial distress score is estimated from the bankruptcy prediction model in Beaver et al. (2012). ${ }^{10,11}$

We then estimate the below grouping (Equation 6) and monthly (Equation 7) regressions:

$$
\begin{aligned}
& a_{1}^{*}-a_{1}=c_{0}+c_{1} S E N T_{-} G_{t}+c_{2} \text { PARTITION }_{t}+c_{3} S E N T_{-} G_{t} * \text { PARTITION }_{t}+ \\
& \sum \text { CONTROL_ } G_{t}+\delta_{t} \\
& a_{1}^{*}-a_{1}=c_{0}+c_{1} \text { SENT_M }_{t}+c_{2} \text { PARTITION }_{t}+c_{3} \text { SENT_M }_{t} * \text { PARTITION }_{t}+ \\
& \sum \text { CONTROL_ } M_{t}+\delta_{t}
\end{aligned}
$$

In the grouping analysis, we divide each of the partitioned low versus high samples (e.g., high R\&D and low R\&D) into 100 groups based on the level of sentiment; this leads to 200 groups of observations used for each cross-sectional analysis. In the monthly analysis, we group observations in each of the partitioned low versus high samples by month/year based on firm's fiscal quarter end. We define PARTITION ${ }_{t}$ as an indicator variable equal to one for the high R\&D, high growth, larger negative special items, or high financial distress group, and zero otherwise. Across both Equations (6) and (7), we predict a non-zero coefficient on the interaction between

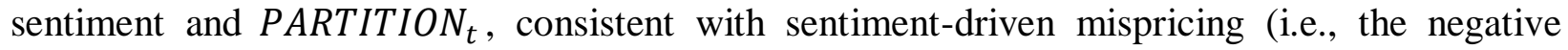
coefficient on $S E N T_{t}$ ) of loss persistence being stronger (either more positive or more negative) for firms characterized as high $\mathrm{R} \& \mathrm{D}$, high growth potential, large negative special items, or high financial distress.

10 This model forecasts the risk of bankruptcy as a function of: return on assets; EBITDA divided by total liabilities; liabilities to assets ratio; lagged market capitalization divided by the market capitalization of the market index; lagged cumulative residual return; and the lagged standard deviation of security returns.

11 We also follow Li (2011) and partition the loss firms into transitory and persistent losses; however, we fail to find significant differences in sentiment effect between these two groups. 


\section{Sample selection and descriptive analyses}

We obtain quarterly financial-statement data from Compustat, stock-return data from CRSP, and the investor sentiment data from Baker and Wurgler (2006) for the period 1973-2015. ${ }^{12}$ We require firm-quarter observations to have non-missing data on return on assets for quarters $t$, $t+1$, and $t-3$; we also require buy-and-hold stock returns for the quarter $t+1$. We exclude observations in the top and bottom one percent of all variables. The sample is $144,765(468,384)$ firm-quarter observations for the loss (profit) sample. We include financial firms in our main analyses; however, all inferences are robust to their exclusion.

Table 1 presents descriptive statistics for loss (Panel A) and profit firms (Panel B). We rank loss (profit) observations into quintiles based on the average sentiment from the month after the earnings announcement of quarter $t$ to the month before the earnings announcement of quarter $t+1$, and report the mean and median of the variables used in the Mishkin test. In Panel A for loss firms, as sentiment increases from the lowest to the highest quintile of sentiment, subsequent mean abnormal returns $\left(X R E T_{t+1}\right)$ decrease from 0.029 to -0.042 ; this is consistent with investors' overvaluation of high sentiment stocks (Baker and Wurgler 2006; Hribar and McInnis 2012). We next report a decreasing trend for $R O A_{t}$ as sentiment increases (from -0.041 in quintile 1 to -0.046 in quintile 5); $R O A_{t+1}$ demonstrates a similar pattern. Together, this suggests that sentiment is negatively associated with contemporaneous and future firm performance. The $t$-test ( $z$-test) comparing means (medians) between quintile 1 and quintile 5 reveals significant differences for all variables. These findings extend prior research by showing that sentiment is not only associated with future returns, but also with firms' operating performance.

12 The sample period starts in 1973 as earnings announcement dates are unavailable prior to this point; it ends in 2015 as this is the last available year for investor sentiment data (downloaded in December 2018). 
Panel B presents the summary statistics for profit firms; we fail to find a monotonic change in $X R E T_{t+1}$ from quintile 1 to quintile 5 . Focusing on the mean difference between quintiles 1 and 5 for $X R E T_{t+1}$ across the loss and profit firms, our results confirm prior evidence suggesting that the sentiment-driven mispricing (i.e., the negative relation between sentiment and future returns) is stronger for loss firms. Specifically, Panel A for loss firms reveals a decrease in mean abnormal returns in quarter $t+1$ of 0.071 (0.029 in quintile 1 less -0.042 in quintile 5), while Panel B for profit firms reveals a decrease of 0.005 (0.021 in quintile 1 less 0.016 in quintile 5); further, Panel B reveals no monotonic change from quintile 1 to quintile 5.

\section{Empirical Results}

\section{Univariate analysis}

Table 2 presents the errors in investor expectations of future earnings for each sentiment quintile. Panel A presents the results for the loss firms, and reports the earnings response coefficient $(b),{ }^{13}$ the coefficients on firms' actual loss persistence $\left(a_{1}\right)$ and investors' expected loss persistence $\left(a_{1}^{*}\right)$, the errors in investors' expected earnings persistence $\left(a_{1}^{*}-a_{1}\right)$, and chi-square $z$-statistics for the test of $a_{1}^{*}-a_{1}=0$. For the lowest sentiment (quintile $=1$ ), we find that loss firms exhibit an actual loss persistence coefficient of 0.597 , and a perceived loss persistence coefficient of 0.943 . The difference of 0.346 (i.e., the errors in investors' expected earnings persistence $)$ is highly significant $(z$-stat $=53.87)$. This suggests that investors overweigh loss persistence during the periods of low sentiment (i.e., they expect losses to be more persistent than they actually are). In the highest sentiment group (quintile $=5$ ), the $a_{1}^{*}-a_{1}$ difference of -0.364

13 The earnings response coefficient increases from 0.659 (1.200) to 0.932 (1.762) for loss (profit) firms as sentiment increases from quintile 1 to quintile 5; this is consistent with the findings in Mian and Sankaraguruswamy (2012). We do not further investigate the mechanism behind the increased ERC. 
also is highly significant $(z$-stat $=150.12)$; of note, in contrast to the low sentiment finding, this latter result suggests that investors underweigh loss persistence during periods of high sentiment (i.e., they expect losses to be less persistent than they actually are). We further observe a monotonic decrease in $a_{1}^{*}-a_{1}$ as sentiment moves from the lowest to the highest quintile. Overall, this decreasing pattern is consistent with a negative relation between sentiment and errors in investor expectations of future earnings, providing univariate support for $\mathrm{H}_{1 \mathrm{~A}}$.

Panel B presents results for the profit firms. We find a significantly negative $a_{1}^{*}-a_{1}(-$ 0.470, $z$-stat $=184.37)$ in the lowest quintile, consistent with investors underweighing profit persistence during periods of low sentiment. We find similar undervaluation of profit persistence in quintiles 2-4. In addition, we find that investors overweigh profit persistence during periods of high sentiment in quintile 5, though the difference of 0.076 is small in magnitude $(z$-stat $=9.33)$. Overall, we find a positive relation between sentiment and expectation errors for profit firms; thus, we provide some univariate support for $\mathrm{H}_{1 \mathrm{~B}}$. However, we fail to observe a fully monotonic increase in $a_{1}^{*}-a_{1}$ as sentiment increases, suggesting the sentiment effect on profit firms may not be as prevalent as it appears for loss firms.

\section{Multivariate analysis}

We next examine the relation between sentiment and the errors in investor expectations of future earnings in a multivariate setting. We first focus on the results of the grouping analysis (with variable denoted via _G suffixes). Table 3 presents the results for loss firms (Panel A) and profit firms (Panel B), respectively. In Panel A for loss firms, Column (1) presents results from regressing $a_{1}^{*}-a_{1}$ on sentiment; Column (2) presents results further including the six firmspecific controls. For both regressions $N=100$, reflecting the ranking of firms into 100 equal- 
sized groups based on the value of sentiment; thus, all variables are mean values from each of the 100 groups. We observe a significantly negative coefficient on $S E N T_{-} G_{t}$ in both the single regression $(-0.358, t$-stat $=4.26)$ and the multivariate regression $(-0.406, t$-stat $=3.23)$. This suggests that investors lower (strengthen) their perception of loss persistence in high (low) sentiment periods, consistent with $\mathrm{H}_{1 \mathrm{~A}}$. Economically, the coefficient of -0.406 in Column (2) suggests that a one standard deviation increase in $S E N T_{-} G_{t}$ is associated with a 0.271 decrease in $a_{1}^{*}-a_{1}\left(-0.406 * 0.667\right.$, the standard deviation of $S E N T_{-} G_{t}$ for loss firms). The only significant control variable in Column (2) is percentage of tangible assets $(-6.230, t$-stat $=1.84)$, indicating that investors overweigh loss persistence for firms with higher amounts of tangible assets.

Panel B presents the grouping analysis results for the profit firms. In Column (3), the coefficient on $S E N T_{-} G_{t}$ is significantly positive $(0.198, t$-stat $=3.76)$; similar results obtain in the multivariate regression of Column (4) $(0.266, t$-stat $=4.69)$. Both results are consistent with high sentiment strengthening investors' perception of profit persistence, and thus support $\mathrm{H}_{1 \mathrm{~B}}$. Regarding economic significance, the coefficient of 0.266 in Column (4) suggests that a one standard deviation increase in $S E N T_{-} G_{t}$ is associated with a 0.200 increase in $a_{1}^{*}-a_{1}(0.266 *$ 0.752 , the standard deviation of $S E N T_{-} G_{t}$ for profit firms). Among the control variables, the coefficients on both sales growth and stock volatility are significantly negative, suggesting that investors perceive lower profit persistence for higher growth and high volatility firms.

In Panel C, we compare the magnitude of the sentiment effect on profit and loss firms. As the coefficient on $S E N T_{-} G_{t}$ has a different predicted sign across these two groups, we conduct a $t$-test comparing the absolute value of these two coefficients. We find that the sentiment effect is stronger for loss firms relative to profit firms both within the regression without control variables 
(i.e., 0.358 in Column (1) versus 0.198 in Column (3); $t$-stat for difference $=1.73$ ) and that with control variables (i.e., 0.406 in Column (2) and 0.266 in Column (4); $t$-stat $=1.70$ ).

We next examine the relation between sentiment and errors in investor expectations of earnings persistence using the monthly analysis. While the previous grouping analysis forms groups based on the level of sentiment regardless of the time period, the current analysis forms groups by aligning sentiment with quarterly earnings announcement date in event time. Thus, each calendar month group has a set of $a_{1}^{*}-a_{1}$, as well as mean values for the six control variables.

Table 4 presents the results. In Panel A for the loss firms, both Columns (1) and (2) are based on a sample of 355 observations; this represents the number of calendar months for which we can obtain $a_{1}^{*}-a_{1}$ from the Mishkin test and the remaining control variables (the $\_M$ suffixes denote variables calculated within the monthly analysis). In Column (1), we find a significantly negative coefficient on $S E N T_{-} M_{t}(-0.122, t$-stat $=2.65)$; similar results obtain in the multivariate regression of Column (2) $(-0.141, t$-stat $=2.96)$. That is, similar to Table 3 , the results suggest that investors lower (strengthen) their perceptions of loss persistence during periods of high (low) sentiment, consistent with $\mathrm{H}_{1 \mathrm{~A}}$. Regarding the control variables, only the proportion of tangible assets is significant $(1.612, t$-stat $=2.41)$. Panel B presents results for the profit sample. In Column (3), we find a significantly positive coefficient on $S E N T_{-} M_{t}(0.124, t$-stat $=2.66)$; similar results again obtain in the multivariate regression of Column (4) $(0.128, t$-stat $=2.54)$. Combined, this provides evidence that high sentiment increases investor expectations of profit persistence, and thus support for $\mathrm{H}_{1 \mathrm{~B}}$. In Panel $\mathrm{C}$, we compare the coefficient on sentiment between profit and loss firms; however, we fail to find significant difference between these two groups. 
Overall, across our grouping and monthly analyses, we find evidence that investor expectations of loss (profit) persistence is negatively (positively) affected by sentiment, with the effect appearing to be stronger for loss firms relative to profit firms.

\section{Cross-sectional analyses for loss firms}

Table 5 presents the cross-sectional results for the grouping analysis examining alternative partitions of differing types of loss firms. Panel A shows the results from the model that regresses $a_{1}^{*}-a_{1}$ only on $S E N T_{-} G_{t}, P A R T I T I O N_{t}$, and $S E N T_{-} G_{t} * P_{\text {PARITION }}$. In Column (1), partitioning on high versus low $R \& D$, the significantly negative coefficient on $S E N T_{-} G_{t}(-0.312$, $t$-stat $=4.70)$ confirms the Table 3 finding that investors overvalue (undervalue) loss persistence in low (high) sentiment periods. In addition, we find a significantly positive coefficient on SENT_G $G_{t}$ PARTITION $(0.266, t$-stat $=2.90)$, suggesting that the overvaluation of loss persistence in low sentiment periods is attenuated for firms characterized by high $R \& D$. Columns (2) - (4) repeat the analysis using as the partitioning variable high growth, large negative special items, and high financial distress, respectively. Focusing on the coefficient for $S E N T_{-} G_{t} *$ PARTITION $_{t}$, we find that the overvaluation of loss persistence in low sentiment periods is also attenuated for high growth firms in Column (2) $(0.287, t$-stat $=2.18)$, and for firms in high financial distress in Column (4) $(0.200, t$-stat $=2.42)$. In Column (3) partitioning on large negative special items, the coefficient is insignificant $(-0.79, t$-stat $=0.89)$. Panel B repeats the analysis with the control variables. Inferences are similar to Panel A: investors overvalue (undervalue) loss persistence in low (high) sentiment periods across all the partitions, and this overvaluation is 
attenuated (as evidenced in a significantly positive interaction term) for firms characterized as high R\&D (Column 1), high growth (Column 2), or high financial distress (Column 4). ${ }^{14}$

Table 6 repeats these cross-sectional partitions using the monthly analysis; results are similar, albeit weaker. We again find a significantly positive coefficient on the interaction of SENT_M ${ }_{t} *$ PARTITION $_{t}$ for the high R\&D indicator in Column (1) in both the regression excluding control variables in Panel A $(0.130 t$-stat $=2.05)$, and including controls in Panel B $(0.125, t$-stat $=1.92)$. In Column (3), we find that the coefficient on the interaction between sentiment and the indicator for large negative special items is significantly positive in both Panel A $(0.228 t$-stat $=2.31)$ and Panel B $(0.188 t$-stat $=1.89)$. The coefficients on the interaction terms are insignificant for either high growth in Column (2), or high distress in Column (4). Combined, the results of Columns (1) and (3) provide some support that the sentiment effect on the mispricing of loss persistence is attenuated for firms with high R\&D or large negative special items. ${ }^{15}$

In summary, the above results suggest that investors consider the nature of the loss in assessing its implications for future earnings. In particular, the results provide support for $\mathrm{H}_{2}$ that sentiment-driven mispricing of loss persistence appears attenuated for firms having high $R \& D$, and some support of similar attenuation for firms having high growth, large negative special items, and high financial distress.

14 In untabulated analysis, we find that correlation coefficients among the four partitioning variables to be small: the highest is between high $R \& D$ and high growth $(0.226)$, and the remaining are below 0.080 . Moreover, we note that $63 \%$ of the loss sample falls within at least one of these partitions, but only $1 \%$ satisfies all four categories.

15 We note that the weaker results for the monthly regressions could reflect fewer observations for each month/year group; specifically, the monthly regression have 500-600 groups (versus 100 groups for the grouping regressions). Having sufficient observations within each group is crucial to generate reliable coefficients from the Mishkin test. 


\section{Sensitivity analyses}

\section{Seasonal Random Walk}

The main analysis adopts the Mishkin framework for earnings persistence between quarters $t$ and $t+1$. We now re-assess our results using a seasonal earnings persistence model between quarters $t-3$ and $t+1$, using the following regressions (corresponding to Equations (1) and (2)): ${ }^{16}$

Forecasting equation: $\quad R O A_{i, t+1}=\alpha_{0}+\alpha_{2} R O A_{i, t-3}+e_{t+1}$

Pricing equation: $\quad B H A R_{i, t+1}=c\left(R O A_{i, t+1}-\alpha_{0}-\alpha_{2}^{*} R O A_{i, t-3}\right)+\varepsilon_{t+1}$

All variables are as defined previously, except that $R O A_{i, t-3}$ is the earnings in the same quarter as $R O A_{i, t+1}$ of the previous year. We then perform the grouping and monthly analyses as follows:

$$
\begin{aligned}
& a_{2}^{*}-a_{2}=c_{0}+c_{2} S E N T_{-} G_{t}+\sum C O N T R O L_{-} G_{t}+\delta_{t} \\
& a_{2}^{*}-a_{2}=c_{0}+c_{2} S E N T T_{-} M_{t}+\sum C O N T R O L_{-} M_{t}+\delta_{t}
\end{aligned}
$$

Again, $a_{2}^{*}-a_{2}$ represents errors in investor expectations of future earnings between quarters $t-3$ and $t+1 ; a_{2}^{*}-a_{2}>0(<0)$ suggests that investors overestimate (underestimate) earnings persistence. As previously, $S E N T_{-} G_{t}\left(S E N T_{-} M_{t}\right)$ is the average sentiment value for each of the 100 groups (each of the calendar month/year groups).

Table 7 presents the results, with the grouping analysis in Panel A. Columns (1) and (2) present the results of loss firms, and Columns (3) and (4) that for profit firms. As expected, we find a significantly negative coefficient on $S E N T_{-} G_{t}$ for loss firms in Column (1) for the regression excluding control variables $(-0.263, t$-stat $=3.03)$, as well as in Column $(2)$ including control

16 For our primary analysis, we focus on the random walk model between two consecutive quarters due to its higher earnings persistence. Specifically, the earnings persistence coefficients for the consecutive random walk model are 0.668 and 0.674 for loss and profit firms, respectively (see Table 2); while the earnings persistence coefficients for the seasonal random walk model are much lower at 0.472 and 0.251 , respectively. 
variables $(-0.346, t$-stat $=2.68)$. These results confirm $\mathrm{H}_{1 \mathrm{~A}}$ using the seasonal earnings persistence model. However, for the profit firms in Columns (3) and (4) (with and without control variables, respectively), $S E N T_{-} G_{t}$ attains unexpected negative coefficients. Finally, Panel C presents results comparing the coefficients across the loss and profit firms, revealing a significantly higher impact of sentiment on loss persistence than profit persistence both when excluding controls (i.e., comparing 0.263 in Column (1) to 0.057 in Column (3)) and including controls (i.e., comparing 0.346 in Column (2) to 0.055 in Column (4)).

Panel B presents the results for the monthly analysis; these are similar to the Panel A results above. Specifically, for loss firms the coefficients on $S E N T_{-} M_{t}$ are significantly negative $(-0.175$, $t$-stat $=3.16$ excluding controls; and $-0.142, t$-stat $=2.47$ including controls $)$. For profit firms the coefficients on $S E N T_{-} M_{t}$ are insignificant. Finally, Panel C again confirms the effect of sentiment on earnings persistence to be larger for loss relative to profit firms.

\section{Controlling for analysts' earnings forecast error}

Hribar and McInnis (2012) correlates analysts' forecast errors with temporal variations in investor sentiment, finding that the sentiment-driven mispricing largely reflects time-series variation in analysts' earnings forecast error. If investors understand and follow analysts' recommendation and forecasts, then our results may reflect sentiment-driven analyst biases (as opposed to our predicted effects, which relate to sentiment-driven earnings expectations). Accordingly, we now control for analyst forecast error, leading to the following modified models:

$$
\begin{aligned}
& a_{1}^{*}-a_{1}=c_{0}+c_{1} S E N T_{-} G_{t}+c_{2} F E_{-} G_{t+1}+\sum \text { CONTROL_G } G_{t}+\delta_{t} \\
& a_{1}^{*}-a_{1}=c_{0}+c_{1} S E N T_{-} M_{t}+c_{2} F E_{-} M_{t+1}+\sum \text { CONTROL_M } M_{t}+\delta_{t}
\end{aligned}
$$


All variables are defined as previously, except analysts forecast error $(F E)$ is the difference between quarter $t+1$ actual earnings and the last analyst consensus forecast before the quarter $t+1$ earnings announcement. $F E_{-} G_{t+1}$ in Equation (12) is the forecast error in the grouping analysis (i.e., the average forecast error for each of 100 sentiment groups); $F E_{-} M_{t+1}$ in Equation (13) is that in the monthly analysis (i.e., the average forecast error for each of the month/year groups).

Table 8 presents the results; again, Panel A (Panel B) presents the grouping (monthly) analysis. In Panel A, the coefficients on analyst forecast error $(F E)$ are insignificant in all regressions. However, the coefficient on $S E N T_{-} G_{t}$ remains significantly negative for loss firms excluding control variables in Column $(1)(-0.370, t$-stat $=4.19)$ and including control variables in Column $(2)(-0.426, t$-stat $=3.34)$. Further, the coefficient is now significantly positive as expected for profit firms when excluding control variables in Column $(3)(0.252, t$-stat $=3.41)$ and including control variables in Column (4) $(0.299$, $t$-stat $=3.81)$. In Panel B, we again find significantly negative coefficients for $S E N T_{-} M_{t}$ in the regressions for loss firms, and significantly positive coefficients for profit firms. Finally, the analyst forecast error is significantly negative in Column (1), and significantly positive in Columns (3) and (4); this suggests that analysts and individual investors overestimate the earnings persistence in the same direction. In Panel $\mathrm{C}$, we compare the coefficient on sentiment between profit and loss firms for the grouping and monthly analyses, respectively; however, we fail to find significant differences between these two groups.

Of note, the results suggest that analyst forecast error does not subsume the shifts in investors' earnings expectation: i.e., investor sentiment remains important after controlling for analyst forecast error. Thus, our results suggest that sentiment has a direct impact on how investors form future earnings expectation, in addition to the intermediating effect provided by analyst forecasts, as argued in Hribar and McInnis (2012). 


\section{Controlling for growth in the Mishkin model}

Two issues regarding the Mishkin test warrant further discussion. First, the Mishkin analyses do not differentiate between the effects of earnings persistence versus growth. Therefore, a high (low) value of $a_{1}^{*}-a_{1}$ can reflect higher (lower) expected persistence and/or higher (lower) expected growth. To better control for the confounding effect of growth and attribute the sentiment effect to expected earnings persistence, we modify our main regressions and control for expectations of earnings growth by including the following six growth variables in the forecasting and pricing equations: book-to-market; quarterly abnormal returns; sales to assets; changes in sales to assets; capital expenditure to assets; and changes in capital expenditure to assets. Untabulated results are qualitatively unchanged for loss firms, and insignificant for profit firms.

Second, Kraft et al. (2007) discusses the effectiveness of the Mishkin test and finds that the omission of some variables from the forecasting and pricing equations can affect inferences. Thus, we test the robustness of our results by including seven variables related to future earnings as suggested by Kraft et al. (2007): sales; changes in sales; capital expenditures; changes in capital expenditures; net operating assets; abnormal returns; and lag return on assets. Table 9 presents the results, with Panel A (Panel B) again presenting the grouping (monthly) analyses. Results are similar to our main findings: loss firms exhibit consistently significantly negative coefficients on SENT; profit firms exhibit significantly positive coefficients (in three of four specifications); and the comparison reveals the loss firms to exhibit larger effects of SENT relative to profit firms in three of four specifications. Overall, we conclude that our previous findings are robust to controlling for the expectation of earnings growth and the additional control variables suggested by Kraft et al. (2007). 


\section{Other Sensitivity Analyses ${ }^{17}$}

While the sentiment index of Baker and Wurgler $(2006,2007)$ is used commonly in accounting research (e.g., Ali and Gurun 2009; Livnat and Petrovits 2009; Hribar and McInnis 2012; Mian and Sankaraguruswamy 2012), it may suffer from measurement error. Accordingly, we use an alternative and widely-applied measure of sentiment: the University of Michigan Consumer Sentiment. This monthly index is calculated by the Michigan Consumer Research Center, using household interviews regarding investors' financial well-being as well as their outlook for the broader economy. Prior literature confirms this index as strongly associated with investor sentiment (Bergman and Roychowdhury 2008; Seybert and Yang 2012). Thus, we alternatively use the University of Michigan Consumer Sentiment in both the univariate and multivariate grouping analysis (Equation 4); untabulated results are similar (though weaker) to those presented.

We also conduct three additional cross-sectional tests. First, Francis et al. (1996) documents that the restructuring charges component of the special items are associated with positive future returns, whereas other special items (such as inventory write-offs) are negatively associated with future returns. Accordingly, we repeat our cross-sectional testing by partitioning negative special items into restructuring charges, write-downs, goodwill impairments, and other special items. However, we fail to find evidence of differential attenuation effects within these four sub-categories. Second, we conduct an additional cross-sectional test for firms with transitory and persistent losses, as defined in $\operatorname{Li}$ (2011); however, we again fail to find evidence of significant differences in sentiment mispricing between these two subgroups. Finally, for completeness, we

17 Results for these analyses are available on request. 
also estimate the Table 5 cross-sectional analyses for the profit firms (i.e., testing whether the sentiment effect on investor expectations of profit persistence differs by high/low R\&D, high/low growth opportunities, etc.). Our results provide no evidence of such differences for profit firms.

We also test whether investor expectations of loss persistence are affected by analyst forecasts for the next quarter. Specifically, we create an indicator variable equal to one if analyst consensus forecasts show a return to profitability for the forthcoming quarter. We then test if investors expect losses to be less persistent if associated with positive analyst forecasts during low sentiment periods. Results on this interaction are again insignificant.

Finally, earnings persistence can be contaminated by the fourth quarter earnings, as firms are more likely to engage in manipulation in the last fiscal quarter (i.e., Q4) to meet or beat earnings targets. ${ }^{18}$ Accordingly, we repeat our main analyses by excluding Q4 related quarters; this focuses the analyses only on the persistence between Q1 and Q2, and Q2 and Q3. Results are unchanged using both grouping and monthly regressions.

\section{Conclusion}

This study documents that sentiment is associated with investor expectations of future earnings. We use the Mishkin (1983) framework to measure investors' expected future earnings given current period's earnings, which enables examination of how sentiment affects investors' valuation of positive and - more importantly—negative earnings. The results reveal that investors overvalue loss persistence during periods of low sentiment, and undervalue loss persistence during periods of high sentiment. We also find similar (though weaker) results of a converse relation

18 In particular, earnings involving Q4 can have a lower persistence if firms engage in manipulations such as "big bath" reporting. On the other hand, earnings involving Q4 can have a higher persistence if firms engage in income smoothing activities. From investors' perspective, if they anticipate the lower (higher) earnings persistence related to Q4, they may adjust their assessment of earnings persistence accordingly. 
using profit observations: investors overvalue (undervalue) profit persistence during periods of high (low) sentiment. We further document that the effects of sentiment on earnings persistence appear stronger for loss relative to profit firms. These findings extend Mian and Sankaraguruswamy (2012) by providing direct evidence that the sentiment effect is stronger for loss firms, consistent with expectations in Baker and Wurgler $(2006,2007)$ that the sentiment effects should be most pronounced for firms that are hard-to-value and difficult to arbitrage (such as loss firms). We also show predictable variation in sentiment-driven mispricing for loss firms: the effect is attenuated if the losses are associated with high $\mathrm{R} \& \mathrm{D}$, high growth potential, larger negative special items, and severe financial distress, all of which are suggestive of improved future performance. Overall, these results reveal a new channel for sentiment-driven mispricing: while Mian and Sankaraguruswamy (2012) shows that the positive relation between sentiment and ERC is a result of its impact on market reaction to per unit of earnings, our results suggest that the mispricing can be caused by the magnitude of earnings surprises through investors' formation of earnings expectations. Finally, our study complements Hribar and McInnis (2012) by capturing investor expectations on future earnings using the Mishkin framework instead of relying on analyst forecasts, which do not separate expected earnings persistence from growth and can also reflect analysts' behavioral biases. 


\section{References}

Abreu, D., and M. K. Brunnermeier. 2003. Bubbles and Crashes. Econometrica 71: 173-204.

Ali, A., and U. Gurun. 2009. Investor Sentiment, Accruals Anomaly, and Accruals Management. Journal of Accounting, Auditing \& Finance 24: 415-431.

Bagnoli, M., M. Clement, M. Crawley, and S. Watts. 2014. The Relative Profitability of Analysts' Stock Recommendations: What Role Does Investor Sentiment Play? Working Paper.

Baker, M., and J. Wurgler. 2006. Investor Sentiment and the Cross-Section of Stock Returns. Journal of Finance 61: 1645-1680.

Baker, M., and J. Wurgler. 2007. Investor Sentiment in the Stock Market. Journal of Economic Perspectives 21: 129-151.

Barth, M. E., Beaver, W. H., and W. R. Landsman. 1998. Relative Valuation Roles of Equity Book Value and Net Income as a Function of Financial Health. Journal of Accounting and Economics 25: 1-34.

Beaver W.H, M. Correia, and M. McNichols. 2012. Do Differences in Financial Reporting Attributes Impair the Predictive Ability of Financial Ratios for Bankruptcy? Review of Accounting Studies 17: 969-1010.

Berger, P. G., Ofek, E., and I. Swary. 1996. Investor Valuation of the Abandonment Option. Journal of Financial Economics 42: 257-287.

Bergman, N., and S. Roychowdhury. 2008. Investor Sentiment and Corporate Disclosure. Journal of Accounting Research 46: 105-1083.

Brown, G. W., and M. Cliff. 2005. Investor Sentiment and Asset Valuation. The Journal of Business 78: 405-440.

Burger, M. and A. Curtis. 2017. Aggregate Margin Debt and the Divergence of Price from Accounting Fundamentals. Contemporary Accounting Research 34:1418-1445.

Burgstahler, D., and Dichev, I. 1997. Earnings Manamgent to Avoid Earnings Decreases and Losses. Journal of Accounting and Economics 24: 99-126

Burgstahler, D., J. Jiambalvo, and T. Shevlin. 2002. Do Stock Prices Fully Reflect the Implications of Special Items for Future Earnings? Journal of Accounting Research 40: 585612.

Collins, D., and S. P. Kothari. 1989. An Analysis of Intertemporal and Cross-Sectional Determinants of Earnings Response Coefficients. Journal of Accounting Economics 11: 143181.

Collins, W., L. Maydew, and S. Weiss. 1997. Changes in the Value-Relevance of Earnings and Book Values Over the Past Forty Years. Journal of Accounting \& Economics 24: 39-67.

Coulton, J., Dinh, T., and Jackson, A. 2016. The Impact of Sentiment on Price Discovery. Accounting and Finance 56: 669-694.

Cready, W. M., T. J. Lopez, and C.A. Sisneros. 2012. Negative Special Items and Future Earnings: Expense Transfer or Real Improvements? The Accounting Review 87: 1165-1195. 
Curtis, A. 2012. A Fundamental-Analysis-Based Test for Speculative Prices. The Accounting Review 87: 121-148.

Darrough, M and J. Ye. 2007. Valuation of Loss Firms in a Knowledge-Based Economy. Review of Accounting Studies 12: 61-93.

D'Avolio, G. 2002. The Market of Borrowing Stock. Journal of Financial Economics 66: 271306.

Dechow, P., and W. Ge. 2006. The Persistence of Earnings and Cash Flows and the Role of Special Items: Implications for the Accrual Anomaly. Review of Accounting Studies 11: 253296.

Dugar, A., and S. Nathan. 1995. The Effect of Investment Banking Relationships on Financial Analysts' Earnings Forecasts and Investment Recommendations. Contemporary Accounting Research 12(1): 131-160.

Easton, P. D., and G. A. Sommers. 2007. Effect of Analysts' Optimism on Estimates of the Expected Rate of Return Implied by Earnings Forecasts. Journal of Accounting Research 45(5): 983-1015.

Edwards, W. 1968. Conservatism in Human Information Processing. Formal Representation of Human Judgment. New York: Wiley.

Fiske, T., and S. Taylor. 1991. Social Cognition (2nd ed.). New York: McGraw Hill.

Francis, J., D. Hanna and L. Vincent. 1996. Causes and Effects of Discretionary Asset Writeoffs. Journal of Accounting Research 34: 117-134.

Francis, J. and D. Philbrick. 1993. Analysts' Decisions As Products of a Multi-Task Environment. Journal of Accounting Research 31: 216-230.

Franzen, L., and S. Radhakrishnan. 2009. The Value Relevance of R\&D Across Profit and Loss Firms. Journal of Accounting and Public Policy 28: 16-32.

Geczy, C., D. Musto, and A. Reed. 2002. Stocks Are Special Too: An Analysis of the Equity Leading Market. Journal of Financial Economics 66: 241-269.

Hayn, C. 1995. The information content of losses. Journal of Accounting and Economics 20: 125-153.

Hengelbrock, J., Theissen, E., and Westheide, C. 2013. Market Response to Investor Sentiment. Journal of Business Finance and Accounting 40: 901-917.

Hribar, P., and I. McInnis. 2012. Investor Sentiment and Analysts' Earnings Forecast Errors. Management Science 58: 293-307.

Hou, K., M. van Dijk, and Y. Zhang. 2012. The Implied Cost of Equity: A New Approach. Journal of Accounting \& Economics 53: 504-526.

Hwang, L., Jan, C., and S. Basu. 1996. Loss Firms and Analysts' Earnings Forecast Errors. The Journal of Financial Statement Analysis 1: 18-30.

Jones, C., and O. Lamont. 2002. Short Sale Constraints and Stock Returns. Journal of Financial Economics 66: 207-239.

Joos, P. and G. Plesko. 2005. Valuing Loss firms. The Accounting Review 80: 847-870. 
Kaplanski, G. and H. Levy. 2017. Analysts and Sentiment: A Causality Study. The Quarterly Review of Economics and Finance 63: 315-327.

Keskek, S., J. N. Myers and L. A. Myers. 2019. Investors' Misweighting of Firm-level Information and the Market's Expectations of Earnings. Working Paper.

Kraft, A., L. Andrew, and C. Wasley. 2007. Regression-based Tests of the Market Pricing of Accounting Numbers: the Mishkin test and Ordinary Least Squares. Journal of Accounting Research: 45: 1081-1114.

Lawrence, A., R. Sloan, and E. Sun. 2017. Why Are Losses Less Persistent than Profits? Curtailments vs. Conservatism. Management Science 63: 1-22.

Lemmon, M., and E. Portniaguina. 2006. Consumer Confidence and Asset Prices: Some Empirical Evidence. Review of Financial Studies 19: 1499-1529.

Li, K. 2011. How Well Do Investors Understand Loss Persistence? Review of Accounting Studies 16: 630-667.

Li, K., and P. Mohanram. 2014. Evaluating Cross-Sectional Forecasting Models for Implied Cost of Capital. Review of Accounting Studies 19: 1152-1185.

Lin, H. W., and M. F. McNichols. 1998. Underwriting Relationships, Analysts' Earnings Forecasts and Investment Recommendations. Journal of Accounting \& Economics 25(1): $101-127$.

Livnat, J., and C. Petrovits. 2009. Investor Sentiment, Post-earnings Announcement Drift, and Accruals. Working Paper, New York University and College of William and Mary.

Lord, C., L. Ross, and M. Lepper. 1979. Biased Assimilation and Attitude Polarization: The Effects of Prior Theories on Subsequently Considered Evidence. Journal of Personality and Social Psychology 37: 2098-2109.

McNichols, M., and P. C. O’Brien. 1997. Self-selection and Analyst Coverage. Journal of Accounting Research 35: 167-199.

Mian G., and S. Sankaraguruswamy. 2012. Investor Sentiment and Stock Market Response to Earnings News. The Accounting Review 87: 1357-1384.

Mishkin, F. 1983. A Rational Expectations Approach to Macroeconometrics: Testing Policy Effectiveness and Efficient Markets Models. Chicago, IL: University of Chicago Press for the National Bureau of Economic Research.

Nichols, D. N., J. M. Wahlen, and M. M. Wieland. 2017. Pricing and Mispricing of Accounting Fundamentals in the Time-Series and in the Cross-Section. Contemporary Accounting Research 34: 1378-1417

Nisbett, R., and L. Ross. 1980. Human Inference: Strategies and Shortcomings of Social Judgment. Prentice-Hall (Englewood Cliffs, NJ).

Richardson, S., S. H. Teoh, and P. Wysocki. 2004. The Walk-down to Beatable Analyst Forecasts: The Role of Equity Issuance and Insider Trading Incentives. Contemporary Accounting Research 21(4): 885-924. 
Riedl, E., and S. Srinivasan. 2010. Signaling Firm Performance Through Financial Statement Presentation: An Analysis Using Special Items. Contemporary Accounting Research 27: 289332.

Seybert, N., and H. Yang. 2012. The Party's Over: The Role of Earnings Guidance in Resolving Sentiment-driven Overvaluation. Management Science 28: 308-319.

Sloan, R. 1996. Do Stock Prices Fully Reflect Information in Accruals and Cash Flows About Future Earnings? The Accounting Review 71: 289-315.

Subramanyam, K., and J. Wild. 1996. Going-Concern Status, Earnings Persistence, and Informativeness of Earnings. Contemporary Accounting Research 13: 251-273.

Walther, B. R. and R. Willis. 2013. Do investor expectations affect sell-side analysts' forecast bias and forecast accuracy? Review of Accounting Studies 18:207-227.

Wooldridge, J. 2013. Introductory Econometrics: A Modern Approach ( $5^{\text {th }}$ edition). SouthWestern.

Xie, H. 2001. The Mispricing of Abnormal Accruals. The Accounting Review 76: 357-373. 
Appendix

Variable Definitions

\begin{abstract}
Main variables (Tables 1 and 2)
$S_{E N T_{t}}$ the average Baker and Wurgler (2006) sentiment index from the month after earnings announcement of quarter $t$ to the month before the earnings announcement of quarter $t+1$;

$R O A_{t} \quad$ firm $i$ 's income before extraordinary items for quarter $t$, divided by total assets at the beginning of quarter $t$;

$R O A_{t+1} \quad$ firm $i$ 's income before extraordinary items for quarter $t+1$, divided by total assets at the beginning of quarter $t+1$;

$X R E T_{t+1}$ firm $i$ 's value-weighed abnormal returns over the period, starting two trading days after the earnings announcement date of quarter $t$ and ending one trading day after the earnings announcement date of quarter $t+1$;

$a_{1} \quad$ the actual earnings persistence coefficient between quarter $t$ and quarter $t+1$;

$a_{1} * \quad$ the expected earnings persistence coefficient between quarter $t$ and quarter $t+1$, obtained from the Mishkin test;
\end{abstract}

\title{
Variables used in the grouping regression (Table 3)
}

$a_{1} \quad$ the actual earnings persistence coefficient between quarter $t$ and quarter $t+1$ for each of the 100 groups; the 100 groups are equally formed based on $S E N T_{t}$;

$a_{1} * \quad$ the expected earnings persistence coefficient between quarter $t$ and quarter $t+1$, obtained from the Mishkin test for each of the 100 groups;

$S E N T_{-} G_{t} \quad$ the average $S E N T_{t}$ for each of the 100 groups;

SIZE_G $G_{t} \quad$ the average log of market capitalization for each of the 100 groups; market capitalization is defined as firm $i$ 's price per share at the end of quarter $t$ multiplied by the number of shares outstanding in quarter $t$;

$S G_{-} G_{t} \quad$ the average sales growth for each of the 100 groups; sales growth is defined as firm $i$ 's sales in quarter $t$ minus sales in quarter $t-1$ divided by sales in quarter $t-1$;

$A G E_{-} G_{t} \quad$ the average number of years since the firm first appeared on CRSP, measured to the nearest month for each of the 100 groups;

$D I V_{-} G_{t} \quad$ the average total dividend in quarter $t$ divided by the book value of equity in quarter $t$ for each of the 100 groups;

$V O L A_{-} G_{t} \quad$ the average standard deviation of daily returns over the three months in quarter $t$ for each of the 100 groups;

$P P E_{-} G_{t} \quad$ the average property, plant, and equipment in quarter $t$, divided by total assets in quarter $t$ for each of the 100 groups;

\section{Variables used in the monthly regression (Table 4)}

$a_{1} \quad$ the actual earnings persistence coefficient between quarter $t$ and quarter $t+1$ for each of the calendar month/year group;

$a_{1} * \quad$ the expected earnings persistence coefficient between quarter $t$ and quarter $t+1$, obtained from the Mishkin test for each of the calendar month/year group;

$S E N T_{-} M_{t} \quad$ the average $S E N T_{t}$ for each of the calendar month/year group; 
$S I Z E \_M_{t} \quad$ the average log market capitalization for each of the calendar month/year group; market capitalization is defined as firm $i$ 's price per share at the end of quarter $t$ multiplied by the number of shares outstanding in quarter $t$;

$S G_{-} M_{t} \quad$ the average sales growth for each of the calendar month/year group; sales growth is defined as firm $i$ 's sales in quarter $t$ minus sales in quarter $t-1$, divided by sales in quarter $t-1$;

$A G E_{-} M_{t} \quad$ the average number of years since the firm first appeared on CRSP, measured to the nearest month for each of the calendar month/year group;

$D I V \_M_{t} \quad$ the average total dividend in quarter $t$, divided by the book value of equity in quarter $t$ for each of the calendar month/year group;

$V O L A \_M_{t} \quad$ the average standard deviation of daily returns over the three months in quarter $t$ for each of the calendar month/year group;

$P P E_{-} M_{t} \quad$ the average property, plant, and equipment in quarter $t$, divided by total assets in quarter $t$ for each of the calendar month/year group;

Variables used in the cross-sectional analyses (Tables 5 and 6)

$R D_{t} \quad$ an indicator variable equal to 1 if firm $i$ 's R\&D in quarter $t$ divided by total assets in quarter $t$ is in the top quartile (high R\&D observations), and 0 otherwise; missing $R \& D$ are set to zero;

$\mathrm{GROWTH}_{t}$ an indicator variable equal to 1 if firm $i$ 's book value of equity in quarter $t$ divided by market capitalization in quarter $t$ is in the bottom quartile (high growth observations), and 0 otherwise;

$S P I_{t} \quad$ an indicator variable equal to 1 if firm $i$ 's special items in quarter $t$ divided by total assets in quarter $t$ is in the bottom quartile (large negative special items observations), and 0 otherwise;

DISTRESS $_{t}$ an indicator variable equal to 1 if firm $i$ 's financial distress score calculated annually for the prior fiscal year is in the bottom quartile (high financial distress observations), and 0 otherwise; financial distress score is calculated using the estimated regression coefficients from the bankruptcy prediction model in Beaver et al. (2012). The prediction model forecasts the risk of bankruptcy as a function of return on assets, EBITDA divided by total liabilities, liabilities to assets ratio, lagged market capitalization divided by the market capitalization of the market index, lagged cumulative residual return, and the lagged standard deviation of security returns;

\section{Variables used in the additional analysis (Tables $\mathbf{7}$ and 8)}

$R O A_{t-3} \quad$ firm $i$ 's income before extraordinary items for quarter $t-3$, divided by total assets at the beginning of quarter $t-3$;

$a_{2} \quad$ the actual earnings persistence coefficient between quarter $t-3$ and quarter $t+1$;

$a_{2}{ }^{*} \quad$ the expected earnings persistence coefficient between quarter $t-3$ and quarter $t+1$ obtained from the Mishkin test;

$F E \_G_{t+1} \quad$ the actual earnings in quarter $t+1$ minus the last analyst consensus forecast for quarter $t+1$ for each of the 100 groups; and

$F E_{-} M_{t+1} \quad$ the actual earnings in quarter $t+1$ minus the last analyst consensus forecast for quarter $t+1$ for each of the calendar month/year group. 
TABLE 1

Descriptive statistics of key variables by sentiment quintiles

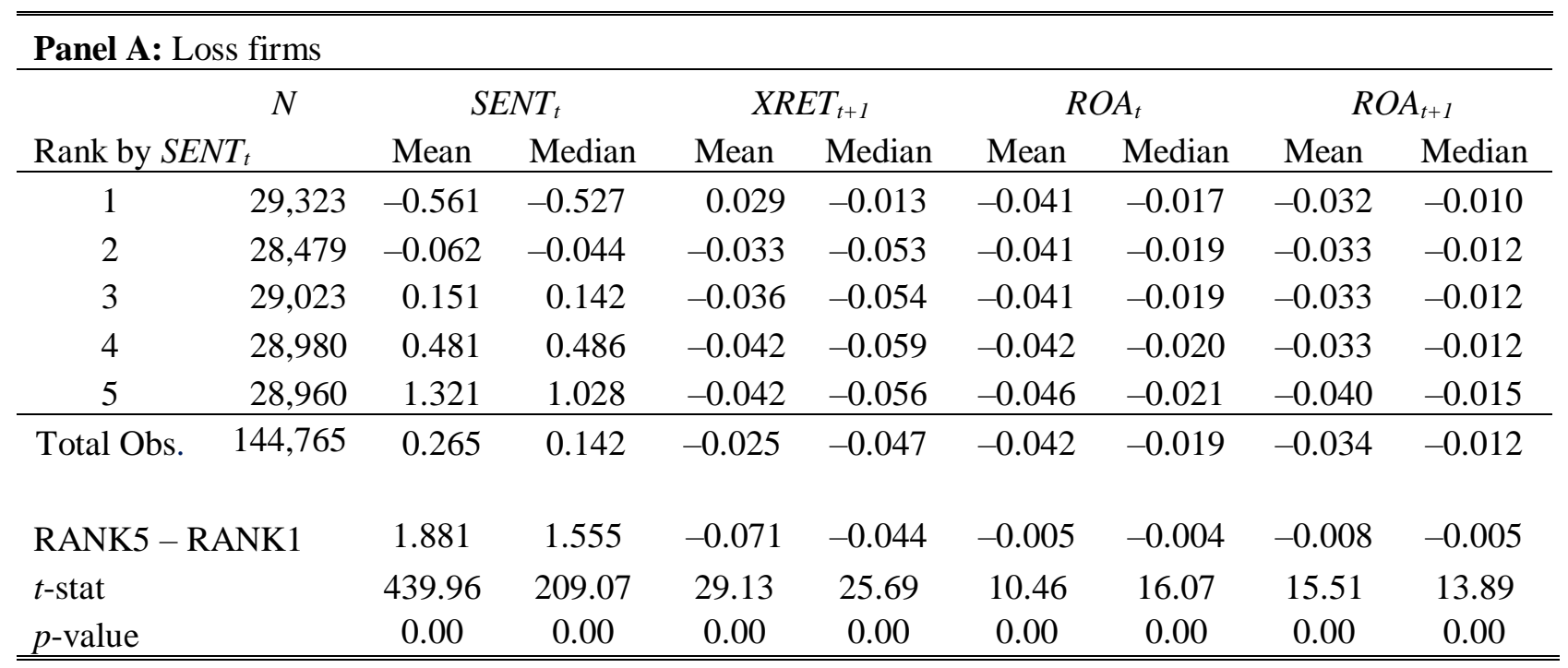

Panel B: Profit firms

\begin{tabular}{|c|c|c|c|c|c|c|c|c|c|}
\hline \multirow{2}{*}{ Rank by $S E N$} & \multirow{2}{*}{$\begin{aligned} & N \\
T_{t} & \end{aligned}$} & \multicolumn{2}{|c|}{$S E N T_{t}$} & \multicolumn{2}{|c|}{$X R E T_{t+1}$} & \multicolumn{2}{|c|}{$R O A_{t}$} & \multicolumn{2}{|c|}{$R O A_{t+1}$} \\
\hline & & Mean & Median & Mean & Median & Mean & Median & Mean & Median \\
\hline 1 & 94,247 & -0.766 & -0.571 & 0.021 & 0.003 & 0.016 & 0.013 & 0.013 & 0.012 \\
\hline 2 & 93,131 & -0.067 & -0.052 & -0.006 & -0.013 & 0.016 & 0.012 & 0.013 & 0.011 \\
\hline 3 & 93,548 & 0.169 & 0.162 & -0.001 & -0.009 & 0.017 & 0.013 & 0.013 & 0.011 \\
\hline 4 & 93,935 & 0.495 & 0.496 & 0.002 & -0.005 & 0.017 & 0.013 & 0.013 & 0.012 \\
\hline 5 & 93,523 & 1.191 & 0.879 & 0.016 & 0.006 & 0.017 & 0.013 & 0.013 & 0.012 \\
\hline Total Obs. & 468,384 & 0.204 & 0.162 & 0.006 & -0.004 & 0.017 & 0.013 & 0.013 & 0.011 \\
\hline RANK5 - I & ANK1 & 1.956 & 1.450 & -0.005 & 0.003 & 0.001 & 0.001 & 0.000 & 0.000 \\
\hline$t$-stat & & 749.45 & 375.27 & 5.63 & 1.72 & 11.76 & 11.87 & 0.79 & 2.20 \\
\hline$p$-value & & 0.00 & 0.00 & 0.00 & 0.08 & 0.00 & 0.00 & 0.43 & 0.03 \\
\hline
\end{tabular}

This table presents the descriptive statistics for the main variables. Panel A (Panel B) presents the summary statistics for loss (profit) firms. Loss (profit) firms are those with income before extraordinary items less than zero (greater than zero). Both loss and profit firms are ranked into quintiles based on the average Baker and Wurgler (2006) sentiment index from the month after earnings announcement of quarter $t$ to the month before the earnings announcement of quarter $t+1$ (SENT $)$. Rank 1 (Rank 5) includes firm-quarter observations in the lowest (highest) sentiment periods. All variables are defined in the Appendix. 
TABLE 2

Univariate analysis

\begin{tabular}{|c|c|c|c|c|c|c|}
\hline Rank by $S E N T_{t}$ & $N$ & $\begin{array}{c}\text { Beta } \\
b \\
\end{array}$ & $\begin{array}{c}\text { Actual } \\
\text { Persistence } \\
a_{1} \\
\end{array}$ & $\begin{array}{c}\text { Expected } \\
\text { Persistence } \\
a_{1}^{*} \\
\end{array}$ & $a_{1}^{*}-a_{1}$ & $z$-stat \\
\hline \multicolumn{7}{|c|}{ Panel A: Loss firms } \\
\hline 1 & 29,323 & 0.659 & 0.597 & 0.943 & 0.346 & $53.87 * * *$ \\
\hline 2 & 28,479 & 0.766 & 0.710 & 0.667 & -0.043 & 1.19 \\
\hline 3 & 29,023 & 0.700 & 0.710 & 0.516 & -0.194 & $20.75 * * *$ \\
\hline 4 & 28,980 & 0.798 & 0.667 & 0.436 & -0.231 & $34.84 * * *$ \\
\hline 5 & 28,960 & 0.932 & 0.665 & 0.300 & -0.364 & $150.12 * * *$ \\
\hline All observations & 144,765 & 0.794 & 0.668 & 0.540 & -0.128 & $58.46 * * *$ \\
\hline \multicolumn{7}{|c|}{ Panel B: Profit firms } \\
\hline 1 & 94,247 & 1.200 & 0.669 & 0.200 & -0.470 & $184.37 * * *$ \\
\hline 2 & 93,131 & 1.630 & 0.667 & 0.405 & -0.262 & $110.78 * * *$ \\
\hline 3 & 93,548 & 1.636 & 0.661 & 0.325 & -0.336 & $193.99 * * *$ \\
\hline 4 & 93,935 & 1.725 & 0.694 & 0.582 & -0.112 & $22.25 * * *$ \\
\hline 5 & 93,523 & 1.762 & 0.685 & 0.761 & 0.076 & $9.33 * * *$ \\
\hline All observations & 468,384 & 1.589 & 0.674 & 0.472 & -0.202 & $298.53 * * *$ \\
\hline
\end{tabular}

This table presents univariate analysis between sentiment and errors in investor expectations of earnings persistence. Panel A (Panel B) presents the results for loss (profit) firms. Loss (profit) firms are those with income before extraordinary items less than zero (greater than zero). $b$ represents the earnings response coefficient, $a_{1}$ represents the actual earnings persistence coefficient, and $a_{1}$ * represents investors' expected earnings persistent coefficient; both are for quarter $t$ to $t+1$, and obtained from the Mishkin test. Both loss and profit firms are ranked into quintiles based on the average Baker and Wurgler (2006) sentiment index from the month after earnings announcement of quarter $t$ to the month before the earnings announcement of quarter $t+1\left(S E N T_{t}\right)$. Rank 1 (Rank 5) includes firm-quarter observations in the lowest (highest) sentiment periods. *, **, *** indicate statistical significance at the $0.10,0.05$, and 0.01 levels, respectively. All variables are defined in the Appendix. 
TABLE 3

Multivariate analysis: grouping regressions

\begin{tabular}{|c|c|c|c|c|c|c|c|c|c|c|}
\hline \multirow[b]{2}{*}{ Variable } & \multicolumn{5}{|c|}{ Panel A: Loss firms } & \multicolumn{5}{|c|}{ Panel B: Profit firms } \\
\hline & Pred Sign & Coefficient & $t$-stat & Coefficient & $t$-stat & Pred Sign & Coefficient & $t$-stat & Coefficient & $t$-stat \\
\hline & & \multicolumn{2}{|c|}{$(1)$} & \multicolumn{2}{|c|}{$(2)$} & \multicolumn{3}{|c|}{ (3) } & \multicolumn{2}{|c|}{ (4) } \\
\hline Intercept & & 0.023 & $(0.36)$ & 6.083 & $(1.30)$ & & -0.278 & $(6.90)^{* * *}$ & 3.091 & $(0.84)$ \\
\hline$S E N T \_G_{t}$ & - & -0.358 & $(4.26)^{* * * *}$ & -0.406 & $(3.23)^{* * * *}$ & + & 0.198 & $(3.76)^{* * * *}$ & 0.266 & $(4.69) * * *$ \\
\hline$S I Z E_{-} G_{t}$ & & & & -0.255 & $(1.26)$ & & & & -0.063 & $(0.36)$ \\
\hline$S G_{-} G_{t}$ & & & & -3.763 & $(1.51)$ & & & & -7.364 & $(2.48)^{* *}$ \\
\hline$A G E_{-} G_{t}$ & & & & -0.042 & $(0.05)$ & & & & -0.265 & $(0.48)$ \\
\hline$D I V \_G_{t}$ & & & & 109.449 & $(0.47)$ & & & & 413.160 & $(0.70)$ \\
\hline$V O L A \_G_{t}$ & & & & 5.906 & $(0.58)$ & & & & -31.583 & $(2.75)^{* * *}$ \\
\hline$P P E \_G_{t}$ & & & & -6.230 & $(1.84)^{*}$ & & & & -1.573 & $(0.63)$ \\
\hline Adj. $R^{2}$ & & \multicolumn{2}{|c|}{0.144} & \multicolumn{2}{|c|}{0.194} & & \multicolumn{2}{|c|}{0.114} & \multicolumn{2}{|c|}{0.187} \\
\hline$N$ & & \multicolumn{2}{|c|}{100} & \multicolumn{2}{|c|}{100} & & \multicolumn{2}{|c|}{100} & \multicolumn{2}{|c|}{100} \\
\hline \multicolumn{11}{|c|}{ Panel C: Comparison between loss and profit firms } \\
\hline \multirow{3}{*}{\multicolumn{2}{|c|}{$\begin{array}{l}\text { Without control variables } \\
\text { With control variables: }\end{array}$}} & & & & & $t$-stat & & & & \\
\hline & & Coeff $($ SEN & $\left.{ }_{-} G_{t}\right)_{\text {loss }}|>| C$ & oeff $\left(\boldsymbol{S E N T} \boldsymbol{T}_{-}\right.$ & t) profit & $(1.73)$ & $* *$ & & & \\
\hline & & Coeff (SEN & $\left.G_{t}\right)_{\text {loss }}|>| \mathrm{C}$ & eeff $\left(S E N T_{-}\right.$ & t)profit & $(1.70)$ & $* *$ & & & \\
\hline
\end{tabular}

This table presents grouping regressions of the relation between sentiment and the errors in investor expectations of earnings persistence (i.e., $a_{1}^{*}-$ $a_{1}$ ). Panel A (Panel B) presents the results for loss (profit) firms. Loss (profit) firms are those with income before extraordinary items less than zero (greater than zero). The initial sample consists of 144,765 loss (468,384 profit) firm-quarter observations, spanning 1973-2015. The loss (profit) sample is ranked equally into 100 groups based on the level of $S E N T_{t}$, and then the Mishkin test is performed for each group. This procedure generates 100 values ( 1 for each group) of $a_{1} *-a_{1}$, the mean value of sentiment, and the mean values of six control variables. Panel $\mathrm{C}$ examines the difference in the sentiment coefficients between profit and loss firm regressions. Because the coefficients have different predicted signs, we compare the absolute value of the coefficients. *,**,*** indicate statistical significance at the $0.10,0.05$, and 0.01 levels, respectively, using two-tailed tests. The key experimental variable is bolded. All variables are defined in the Appendix; the _G suffix denotes variables for the grouping analysis. 
TABLE 4

Multivariate analysis: monthly regressions

$$
\text { Regression: } \quad a_{1}^{*}-a_{1}=c_{0}+c_{1} S E N T_{-} M_{t}+\sum \text { CONTROL_ } M_{t}+\delta_{t}
$$

\begin{tabular}{|c|c|c|c|c|c|c|c|c|c|c|}
\hline Variable & $\begin{array}{c}\text { Panel A: } \\
\text { Predicted } \\
\text { Sign }\end{array}$ & $\begin{array}{l}\text { Loss firms } \\
\text { Coefficient }\end{array}$ & $t$-stat & Coefficient & $t$-stat & $\begin{array}{c}\text { Panel B: } \\
\text { Predicted } \\
\text { Sign }\end{array}$ & $\begin{array}{l}\text { Profit firms } \\
\text { Coefficient }\end{array}$ & $t$-stat & Coefficient & $t$-stat \\
\hline & & \multicolumn{2}{|c|}{$(1)$} & \multicolumn{2}{|c|}{ (2) } & & \multicolumn{2}{|c|}{$(3)$} & \multicolumn{2}{|c|}{ (4) } \\
\hline Intercept & & -0.174 & $(4.74)^{* * *}$ & 0.725 & $(0.75)$ & & -0.230 & $(6.03)^{* * *}$ & -1.727 & $(0.97)$ \\
\hline$S E N T \_M_{t}$ & - & -0.122 & $(2.65)^{* * *}$ & -0.141 & $(2.96)^{* * *}$ & + & 0.124 & $(2.66)^{* * *}$ & 0.128 & $(2.54)^{* *}$ \\
\hline$S I Z E \_M_{t}$ & & & & -0.078 & $(1.69)$ & & & & 0.010 & $(0.12)$ \\
\hline$S G_{-} M_{t}$ & & & & 0.309 & $(0.56)$ & & & & -2.581 & $(2.42)^{* *}$ \\
\hline$A G E \_M_{t}$ & & & & -0.100 & $(0.55)$ & & & & 0.501 & $(1.91)$ \\
\hline$D I V \_M_{t}$ & & & & 99.525 & $(1.24)$ & & & & 103.039 & $(0.51)$ \\
\hline$V O L A \_M_{t}$ & & & & 5.340 & $(1.44)$ & & & & 15.624 & $(2.55)^{* *}$ \\
\hline$P P E \_M_{t}$ & & & & 1.612 & $(2.41)^{* *}$ & & & & -1.134 & $(0.54)$ \\
\hline Adj. $R^{2}$ & & & 16 & & & & $0 .($ & 13 & & 052 \\
\hline$N$ & & & 55 & & & & 3 & 95 & & 95 \\
\hline
\end{tabular}

Panel C: Comparison between loss and profit firms

Without control variables: $\left|\operatorname{Coeff}\left(\boldsymbol{S E N T} \boldsymbol{G}_{\boldsymbol{t}}\right)_{\text {loss }}\right|>\left|\operatorname{Coeff}\left(\boldsymbol{S E N T} \boldsymbol{G}_{\boldsymbol{t}}\right)_{\text {profit }}\right|$

This table presents monthly regressions of the relation between sentiment and the errors in investor expectations of earnings persistence $\left(a_{1}^{*}-a_{1}\right)$. Panel A (Panel B) presents the results for loss (profit) firms. Loss (profit) firms are those with income before extraordinary items less than zero (greater than zero). The initial sample consists of 144,765 loss (468,384 profit) firm-quarter observations, spanning 1973-2015. The loss (profit) sample is divided into calendar month/year groups based on firms' fiscal quarter end; the Mishkin test then is performed for each group. This procedure generates one of the following for each calendar month/year group: $a_{1}{ }^{*}-a_{1}$, the mean value of sentiment, and the mean values of six control variables. Thus, the number of groups depends on the number of calendar month/years with sufficient observations for the Mishkin test. 
Panel C examines the difference in the sentiment coefficients between profit and loss firms. Because the coefficients have different predicted signs, we compare the absolute value of the coefficients. *, **,*** indicate statistical significance at the $0.10,0.05$, and 0.01 levels, respectively, using two-tailed tests. The key experimental variable is bolded. All variables are defined in the Appendix; the _ $M$ suffix denotes variables constructed for the monthly analysis. 
TABLE 5

Cross-sectional analysis: grouping regressions

Regression: $a_{1}^{*}-a_{1}=c_{0}+c_{1} S_{E N T_{-} G_{t}}+c_{2}$ PARTITION $_{t}+c_{3}$ SENT__ $_{t} *$ PARTITION $_{t}+\sum$ CONTROL_$_{-}+\delta_{t}$

\begin{tabular}{|c|c|c|c|c|c|c|c|c|c|}
\hline \multirow{2}{*}{\multicolumn{2}{|c|}{ PARTITION $_{t}=$}} & \multicolumn{2}{|c|}{ High R\&D } & \multicolumn{2}{|c|}{ High Growth } & \multicolumn{2}{|c|}{ Large Negative SPI } & \multicolumn{2}{|c|}{ High Distress } \\
\hline & & Coefficient & $t$-stat & Coefficient & $t$-stat & Coefficient & $t$-stat & Coefficient & $t$-stat \\
\hline \multicolumn{4}{|c|}{ Panel A: Excluding control variables $(N=200$ for all regressions) } & & & \multicolumn{2}{|c|}{ (3) } & \multicolumn{2}{|c|}{$(4)$} \\
\hline Intercept & & -0.158 & $(3.15)^{* * *}$ & 0.085 & $(1.22)$ & -0.179 & $(3.78) * * *$ & -0.088 & $(2.05)^{* *}$ \\
\hline$S E N T_{-} G_{t}$ & - & -0.312 & $(4.70) * * *$ & -0.387 & $(4.23)^{* * *}$ & -0.210 & $(3.38) * * *$ & -0.268 & $(4.89) * * *$ \\
\hline PARTITION $_{t}$ & & -0.154 & $(2.17)^{* *}$ & -0.330 & $(3.28) * * *$ & 0.227 & $(3.31)^{* * *}$ & -0.055 & $(0.86)$ \\
\hline Adj. $R^{2}$ & \multicolumn{3}{|c|}{0.098} & \multicolumn{2}{|c|}{0.108} & \multicolumn{2}{|c|}{0.167} & \multicolumn{2}{|c|}{0.049} \\
\hline \multicolumn{10}{|c|}{ Panel B: Including control variables ( $N=200$ for all regressions) } \\
\hline Intercept & & -0.055 & $(0.02)$ & 0.430 & $(0.14)$ & -2.600 & $(1.02)$ & -3.079 & $(1.47)$ \\
\hline$S E N T \_G_{t}$ & - & -0.363 & $(4.84)^{* * *}$ & -0.529 & $(5.18) * * *$ & -0.272 & $(3.48) * * *$ & -0.247 & $(3.61)^{* * *}$ \\
\hline$A G E \_G_{t}$ & & -0.151 & $(0.46)$ & -0.787 & $(1.56)$ & -0.266 & $(0.74)$ & 0.266 & $(0.80)$ \\
\hline$D I V_{-} G_{t}$ & & -139.239 & $(1.20)$ & 62.640 & $(0.55)$ & 60.521 & $(0.53)$ & -89.388 & $(1.05)$ \\
\hline$V O L A \_G_{t}$ & & 17.538 & $(3.36)^{* * *}$ & 17.054 & $(2.53)^{* *}$ & 7.563 & $(1.32)$ & 15.023 & $(2.91) * * *$ \\
\hline$P P E_{-} G_{t}$ & & 0.025 & $(0.01)$ & 0.741 & $(0.34)$ & 2.181 & $(1.35)$ & 1.450 & $(1.08)$ \\
\hline $\operatorname{Adj} R^{2}$ & \multicolumn{3}{|c|}{0.143} & \multicolumn{2}{|c|}{0.180} & \multicolumn{2}{|c|}{0.168} & \multicolumn{2}{|c|}{0.145} \\
\hline
\end{tabular}

This table presents grouping regressions examining cross-sectional variation on the relation between sentiment and the errors in investor expectations of loss persistence $\left(a_{1}^{*}-a_{1}\right)$. Four partitions are examined: high/low R\&D (Column 1); high/low growth opportunity using book-to-market ratios 
(Column 2); large negative/small negative or zero special items (Column 3); and high/low financial distress (Column 4). Panel A and Panel B present the results with and without control variables, respectively. The initial sample consists of 144,765 loss firm-quarter observations, spanning 1973-2015. The observations within the partitions are as follows: high versus low R\&D (36,191/108,574); high versus low growth opportunities $(38,332 / 106,433)$; large negative special items versus small negative or zero special items $(40,483 / 104,282)$; and high versus low financial distress $(29,230 / 87,685)$. The loss sample is first split based on the cross-sectional variable; each partition (e.g., high R\&D observations) is then ranked equally into 100 groups based on the level of $S E N T_{t}$; and the Mishkin test is performed for each group. This procedure generates one set of $a_{1}^{*}-a_{1}$, the mean value of sentiment, and the mean values of six control variables for each partition group (e.g., high R\&D observations). For example, for the R\&D partition regressions, 100 sets of $a_{1}^{*}-a_{1}$ and the mean values of six control variables are obtained from high R\&D observations, and 100 sets of $a_{1}^{*}-a_{1}$ and the mean values of six control variables are obtained from low R\&D observations; regressions are then run using a total of 200 observations. $*, * *, * * *$ indicate statistical significance at the $0.10,0.05$, and 0.01 levels, respectively, using two-tailed tests. The key experimental variables are bolded. All variables are defined in the Appendix; the_G suffix denotes variables constructed for the grouping analysis. 
TABLE 6

Cross-sectional analysis: monthly regressions

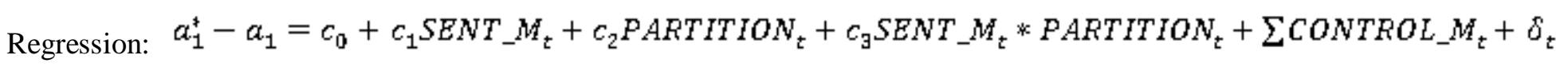

\begin{tabular}{|c|c|c|c|c|c|c|c|c|c|}
\hline \multirow{2}{*}{\multicolumn{2}{|c|}{ PARTITION $_{t}=$}} & \multicolumn{2}{|c|}{ High R\&D } & \multicolumn{2}{|c|}{ High Growth } & \multicolumn{2}{|c|}{ Large Negative SPI } & \multicolumn{2}{|c|}{ High Distress } \\
\hline & & Coefficient & $t$-stat & Coefficient & $t$-stat & Coefficient & $t$-stat & Coefficient & $t$-stat \\
\hline & & \multicolumn{2}{|c|}{$(1)$} & \multicolumn{2}{|c|}{$(2)$} & \multirow{2}{*}{\multicolumn{2}{|c|}{ (3) }} & \multirow{2}{*}{\multicolumn{2}{|c|}{ (4) }} \\
\hline \multicolumn{6}{|c|}{ Panel A: Excluding control variables } & & & & \\
\hline Intercept & & -0.181 & $(6.69)^{* * *}$ & -0.168 & $(3.14)^{* * *}$ & -0.144 & $(2.83)^{* * *}$ & -0.144 & $(2.57)^{* *}$ \\
\hline$S E N T \_M_{t}$ & - & -0.121 & $(3.37)^{* * *}$ & -0.039 & $(0.60)$ & -0.195 & $(3.10)^{* * *}$ & -0.088 & $(1.23)$ \\
\hline PARTITION $_{t}$ & & 0.055 & $(1.27)$ & -0.072 & $(0.87)$ & 0.020 & $(0.27)$ & -0.116 & $(1.41)$ \\
\hline Adj. $R^{2}$ & & \multicolumn{2}{|c|}{0.024} & \multirow{2}{*}{\multicolumn{2}{|c|}{$\begin{array}{c}0.001 \\
707\end{array}$}} & \multicolumn{2}{|c|}{0.010} & \multicolumn{2}{|c|}{0.002} \\
\hline$N$ & & \multicolumn{2}{|c|}{648} & & & \multicolumn{2}{|c|}{733} & \multicolumn{2}{|c|}{718} \\
\hline \multicolumn{6}{|c|}{ Panel B: Including control variables } & & & & \\
\hline Intercept & & 0.583 & $(1.02)$ & -0.854 & $(0.82)$ & 1.621 & $(1.66)$ & 1.097 & $(1.13)$ \\
\hline$S E N T \_M_{t}$ & - & -0.112 & $(3.04)^{* * *}$ & -0.046 & $(0.69)$ & -0.177 & $(2.72)^{* * *}$ & -0.086 & (1.18) \\
\hline$A G E \_M_{t}$ & & -0.009 & $(0.10)$ & 0.044 & $(0.26)$ & -0.074 & $(0.45)$ & -0.072 & $(0.41)$ \\
\hline$D I V \_M_{t}$ & & -68.213 & $(1.82)^{*}$ & 18.546 & $(0.37)$ & 22.815 & $(0.36)$ & 109.265 & $(2.20)^{* *}$ \\
\hline$V O L A \_M_{t}$ & & 0.568 & $(0.28)$ & 2.512 & $(0.66)$ & 2.060 & $(0.57)$ & 1.768 & $(0.49)$ \\
\hline$P P E \_M_{t}$ & & 0.394 & $(0.99)$ & 1.536 & $(2.66)^{* * *}$ & 0.828 & $(1.32)$ & 0.111 & $(0.18)$ \\
\hline $\operatorname{Adj} R^{2}$ & & \multicolumn{2}{|c|}{0.030} & \multicolumn{2}{|c|}{0.003} & \multicolumn{2}{|c|}{0.023} & \multicolumn{2}{|c|}{0.013} \\
\hline$N$ & & \multicolumn{2}{|c|}{648} & \multicolumn{2}{|c|}{707} & \multicolumn{2}{|c|}{733} & \multicolumn{2}{|c|}{718} \\
\hline
\end{tabular}


This table presents monthly regressions examining cross-sectional variation on the relation between sentiment and the errors in investor expectations of loss persistence $\left(a_{1}^{*}-a_{1}\right)$. Four partitions are examined: high/low R\&D (Column 1); high/low growth opportunity using book-to-market ratios (Column 2); large negative/small negative or zero special items (Column 3); and high/low financial distress (Column 4). Panel A and Panel B present the results with and without control variables, respectively. The initial sample consists of 144,765 loss (468,384 profit) firm-quarter observations, spanning 1973-2015. The observations within the partitions are as follows: high versus low R\&D $(36,191 / 108,574)$; high versus low growth opportunities $(38,332 / 106,433)$; large negative special items versus small negative or zero special items $(40,483 / 104,282)$; and high versus low financial distress $(29,230 / 87,685)$. The loss sample is first split based on the cross-sectional variable; each partition (e.g., high R\&D observations) is then divided into calendar month/year groups based on the firms' fiscal quarter ended month; and the Mishkin test is performed for each calendar month/year group. This procedure generates one set of $a_{1}^{*}-a_{1}$, the mean value of sentiment, and the mean values of six control variables for each partition group (e.g., high R\&D observations). For example, for the R\&D partition regressions, 276 sets of $a_{1}^{*}-a_{1}$ and the mean values of six control variables are obtained from high R\&D observations, and 276 sets of $a_{1}^{*}-a_{1}$ and the mean values of six control variables are obtained from low R\&D observations; regressions are then run using a total of 552 observations. *, **, *** indicate statistical significance at the $0.10,0.05$, and 0.01 levels, respectively, using two-tailed tests. The key experimental variables are bolded. All variables are defined in the Appendix; the $\_M$ suffix denotes variables constructed for the monthly analysis. 
TABLE 7

Sensitivity analysis: seasonal random walk

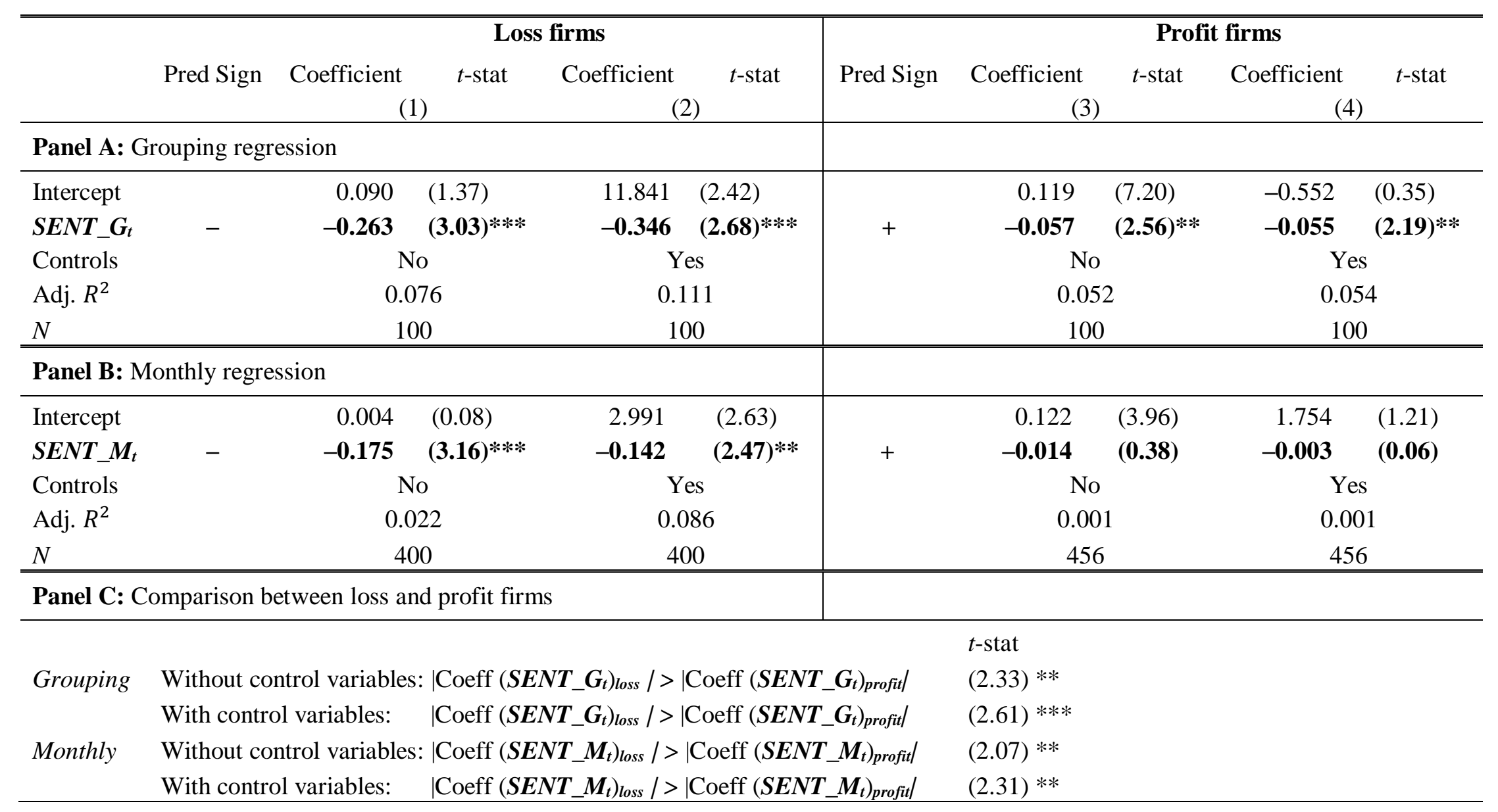

This table presents regressions of the relation between sentiment and the errors in investor expectations of earnings persistence using a seasonal random walk model to assess earnings persistence, measured using quarter $t-3$ and $t+1$. Panels $\mathrm{A}$ and $\mathrm{B}$ present the results for the grouping and monthly regressions, respectively; Panel $\mathrm{C}$ examines the difference in the sentiment coefficients between profit and loss firms. Loss (profit) firms are those with income before extraordinary items less than zero (greater than zero). The initial sample consists of 144,765 loss (468,384 profit) 
firm-quarter observations, spanning 1973-2015. *, **, *** indicate statistical significance at the 0.10, 0.05, and 0.01 levels, respectively, using twotailed tests. The key experimental variables are bolded. All variables are defined in the Appendix. 
TABLE 8

Sensitivity analysis: controlling for analysts' earnings forecast error

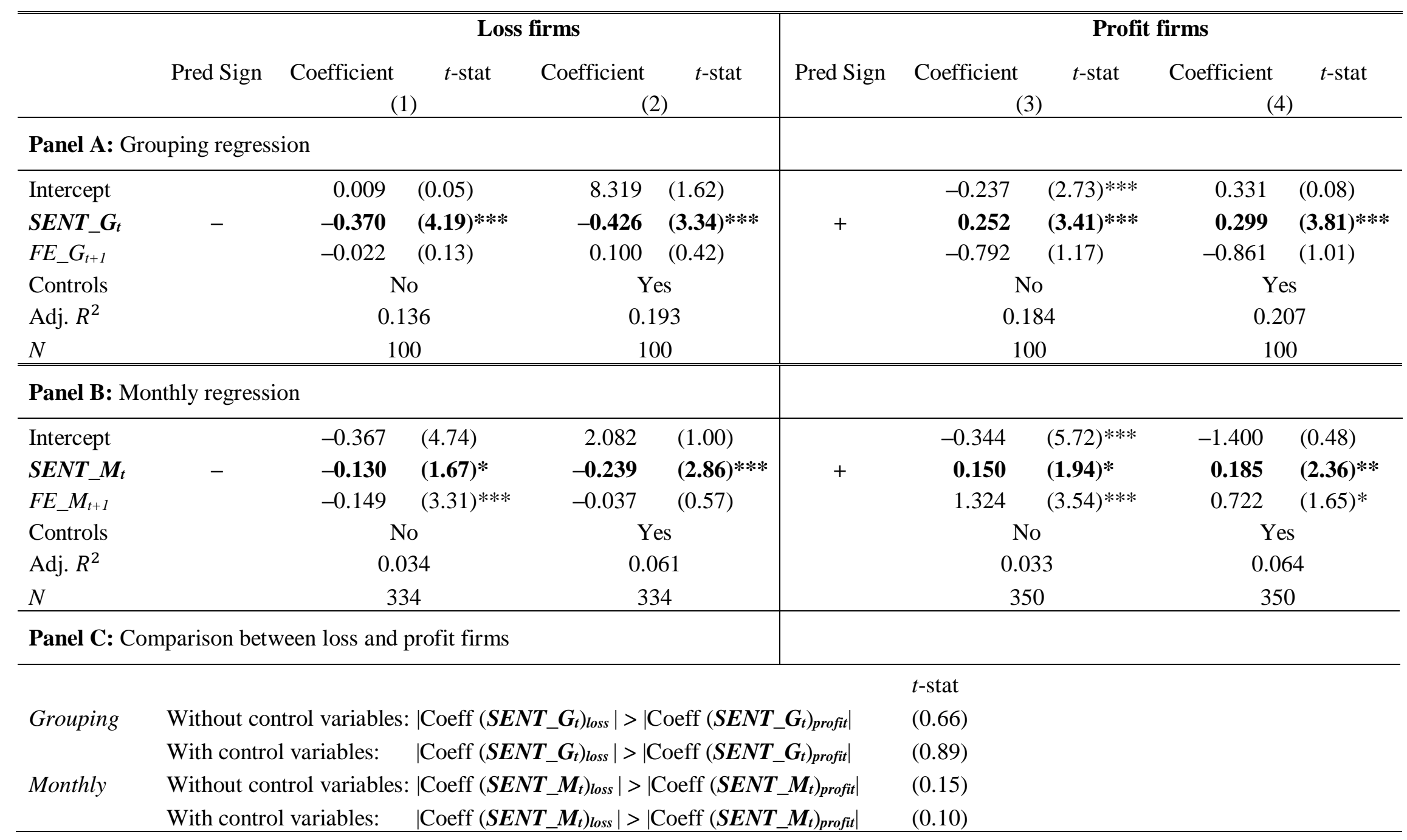


This table presents a regression analysis of the relation between sentiment and the errors in investor expectations of earnings persistence controlling for analysts forecast errors. Analysts forecast errors are defined as actual earnings per share minus the last consensus forecast before the announcement of quarter $t+1$ earnings. Panels A and B present the results for grouping regressions and monthly regressions, respectively; Panel C examines the difference in the sentiment coefficients between profit and loss firms. Loss (profit) firms are those with income before extraordinary items less than zero (greater than zero). The initial sample consists of 144,765 loss (468,384 profit) firm-quarter observations, spanning 1973-2015. $*, * *, * * *$ indicate statistical significance at the $0.10,0.05$, and 0.01 levels, respectively, using two-tailed tests. The key experimental variables are bolded. All variables are defined in the Appendix. 
TABLE 9

Sensitivity analysis: including growth variables in the Mishkin model

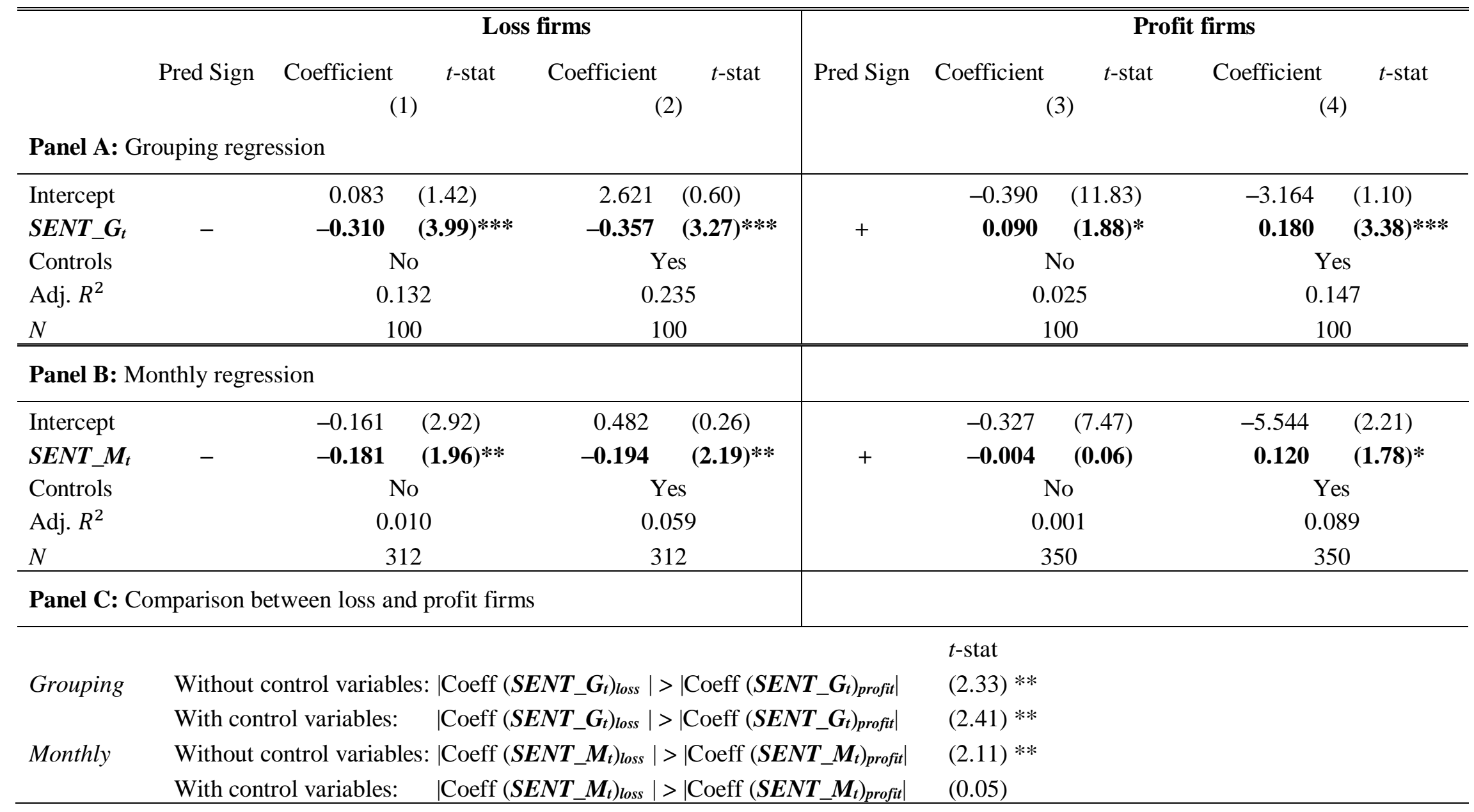

This table presents a regression analysis of the relation between sentiment and the errors in investor expectations of earnings persistence using the dependent variable $a_{1} *-a_{1}$ calculated by adding six growth variables (book-to-market, quarterly abnormal returns, sales to assets, changes in sales to assets, capital expenditure to assets, and changes in capital expenditure to assets) in the forecasting and pricing equations. Panel A and Panel B present the results for grouping regressions and monthly regressions, respectively; Panel $\mathrm{C}$ examines the difference in the sentiment coefficients 
between profit and loss firms. Loss (profit) firms are those with income before extraordinary items less than zero (greater than zero). *, **, *** indicate statistical significance at the 0.10, 0.05, and 0.01 levels, respectively, using two-tailed tests. All variables are defined in the Appendix. 